\title{
(IIAX)
}

Cost Analysis of Fuel Cell Systems for Transportation

Compressed Hydrogen and PEM Fuel Cell System
Final Presentation to:

Fuel Cell Tech Team

FreedomCar

Detroit. MI

October 20, 2004
TIAX LLC

Acorn Park

Cambridge, Massachusetts 02140-2390

\section{Ref D0006}

SFAA No. DE-SCO2-

98EE50526

Topic 1 Subtopic $1 \mathrm{C}$ 
Agenda

\section{Project Overview}

Compressed Hydrogen Storage Cost

\section{System Cost Update}

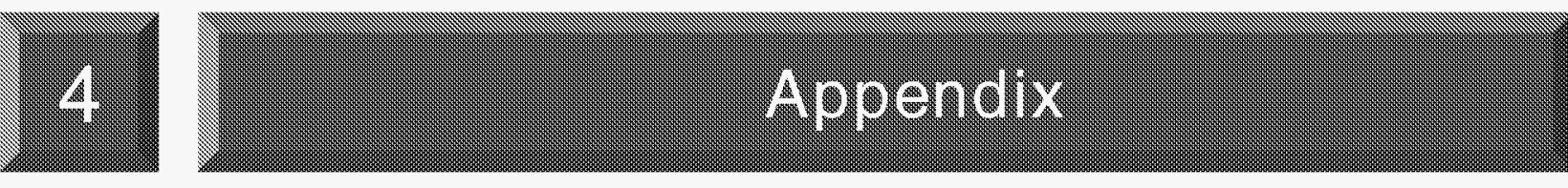


In our final year of the project, we assessed the cost of compressed hydrogen storage and updated the overall system cost projection.

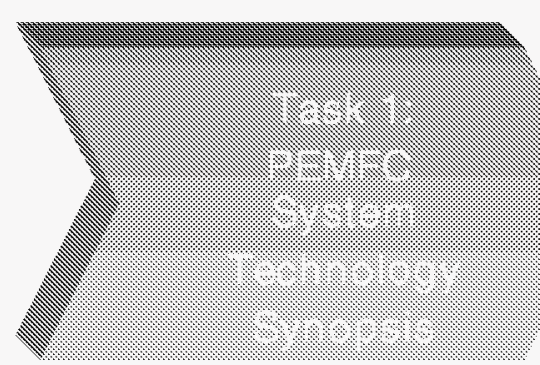

- Develop baseline system specification

- Project technology developments

- Assess impact on system performance

- Identify manufacturing processes

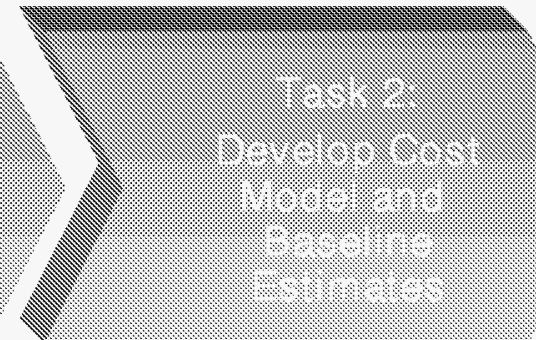

- Develop cost model

- Specify manufacturing processes and materials

- Develop production scenarios

- Baseline cost estimate

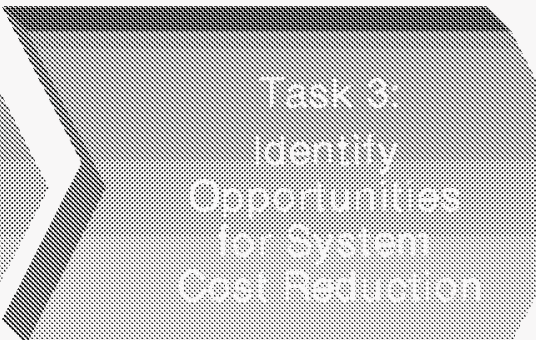

- Perform sensitivity analysis to key parameters

- Evaluate the impact of design parameters and potential technology breakthroughs on subsystem and overall system costs

- Identify and prioritize opportunities for cost reduction in transportation PEMFC systems

Obtain industry feedback

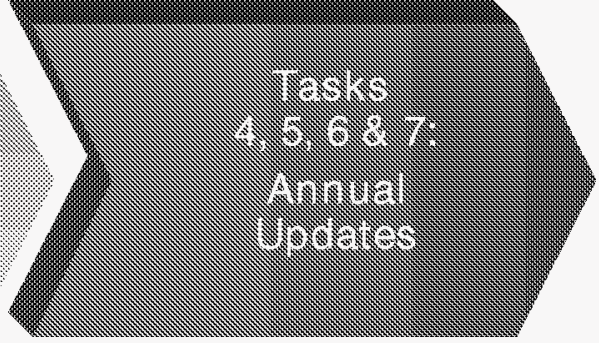

Assess technology evolution

Update baseline cost estimate based on technology developments Year 2 (2000) _ Y Years 3, 4, and 5 
A fuel cell vehicle would contain the PEMFC system modeled in this project along with additional electric drive train components. Components included in the analysis are based on PNGV/FreedomCar guidelines.

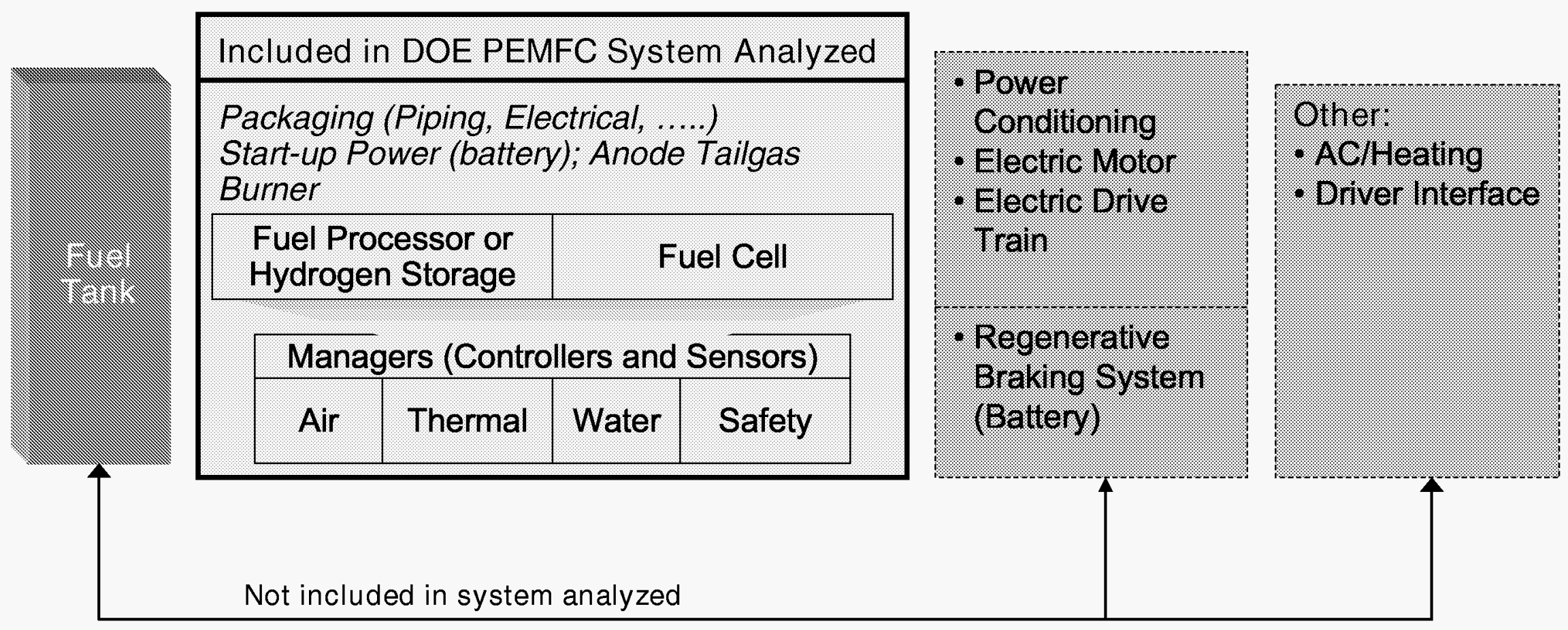

In the direct hydrogen system, the hydrogen storage subsystem replaces the fuel processor. 
Individual components have been distributed between the major subsystems as shown below for the Year 2000/2001 baseline system.

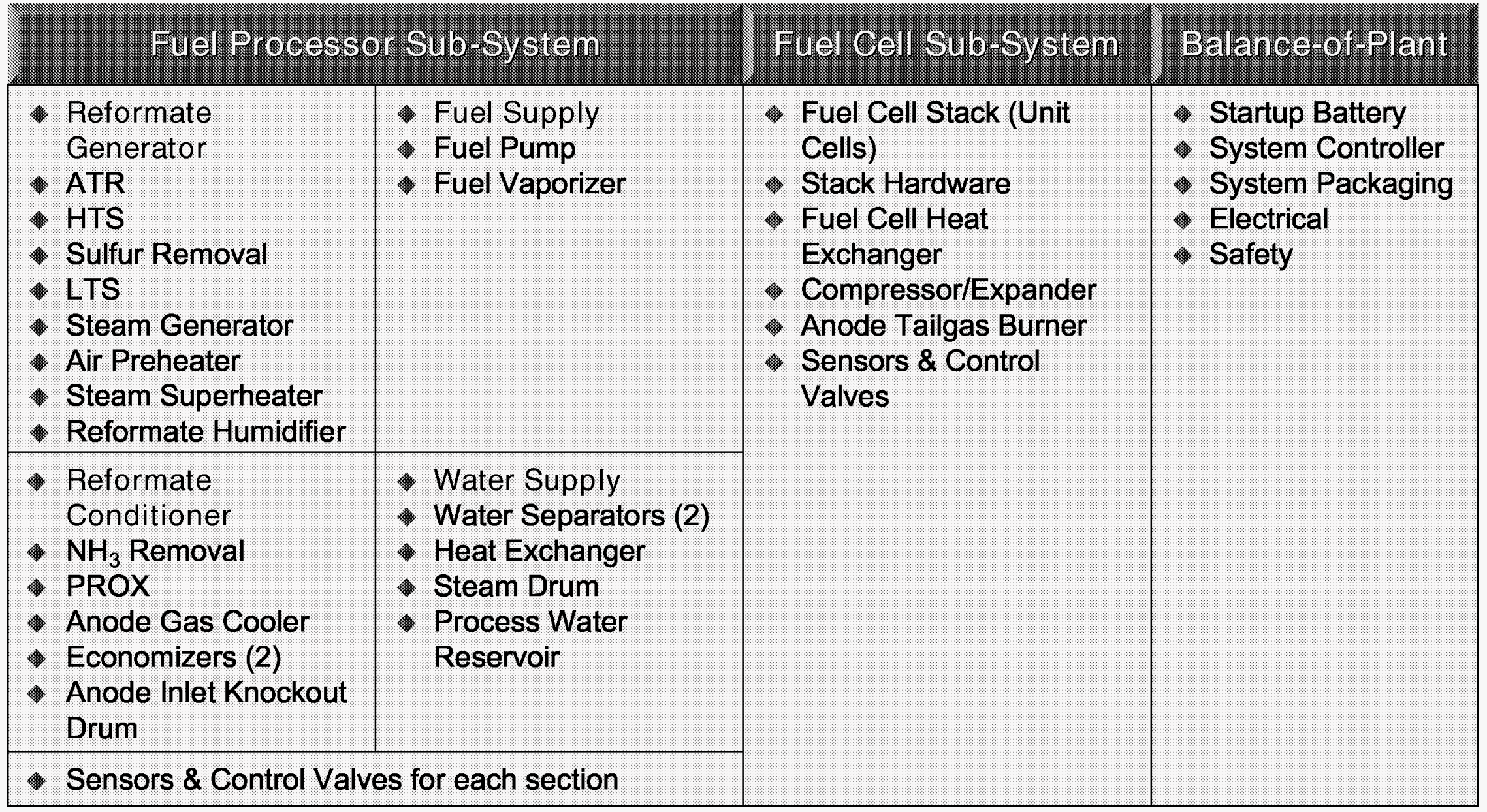

Hydrogen storage replaces the fuel processor but still needs water and thermal management. 


\section{Project Overview Definition of Cost Basis}

We have estimated the system cost up to and including factory costs for annual production volumes of 500,000 .
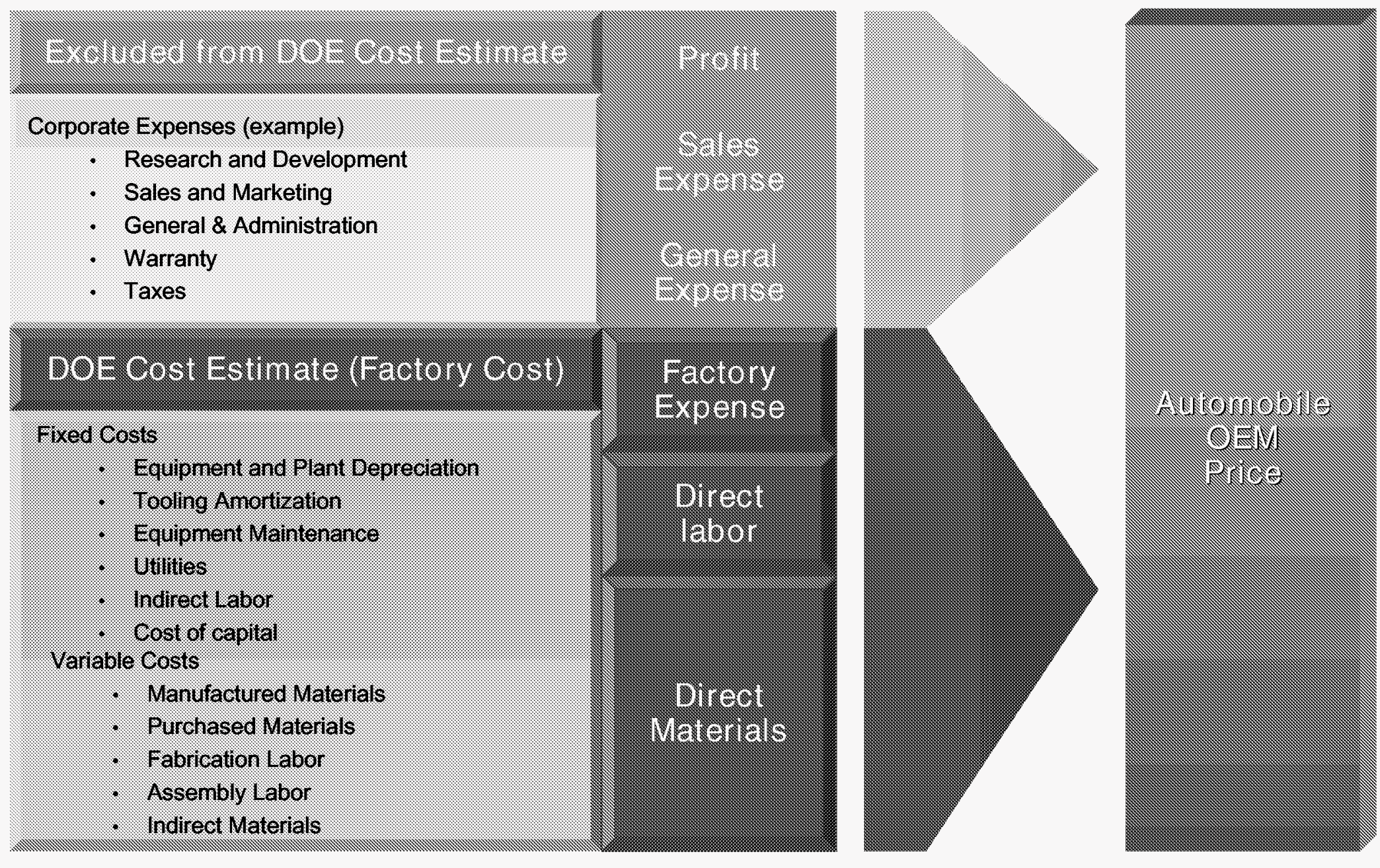
Our early estimates for reformate systems were around $\$ 300 / \mathrm{kW}$ (2000/2001 technology at large production volumes).

\begin{tabular}{|c|c|c|c|c|}
\hline & Erict & Cost Esti & $\mathrm{te}^{\mathrm{x}}$ & \\
\hline \multirow{2}{*}{$\begin{array}{l}\text { Sule } \\
\text { sustern }\end{array}$} & $\begin{array}{l}2000 \\
\text { Baseline }\end{array}$ & $\begin{array}{l}2001 \\
\text { isselline }\end{array}$ & \multirow{2}{*}{ change } & \multirow[t]{2}{*}{ DYM $=1$} \\
\hline & $(3)(x)$ & $(9 / 1 \times)$ & & \\
\hline Fuel Cell & 177 & 221 & +25 & $\begin{array}{l}\text { Electrode and membrane material cost } \\
\text { basis revised resulting in net increase }\end{array}$ \\
\hline $\begin{array}{l}\text { Fuel } \\
\text { Processor }\end{array}$ & 86 & 76 & -12 & Catalyst bed calculation basis revised \\
\hline BOP & 10 & 10 & 0 & No changes to 2000 Baseline \\
\hline $\begin{array}{l}\text { System } \\
\text { Assembly }\end{array}$ & 21 & 17 & -19 & Reduction in assumed welding times \\
\hline Total & 294 & 324 & +10 & $\begin{array}{l}\text { Overall increase due to fuel cell } \\
\text { subsystem cost increase }\end{array}$ \\
\hline
\end{tabular}

*Basis: 50 kWe net, 500,000 units/yr. Not complete without assumptions. 
In 2002 projected improvements in performance and operation on hydrogen led to an estimate of approximately $\$ 100 / \mathrm{kW}$ for the system cost.

\section{Scenarios' Cost Results}

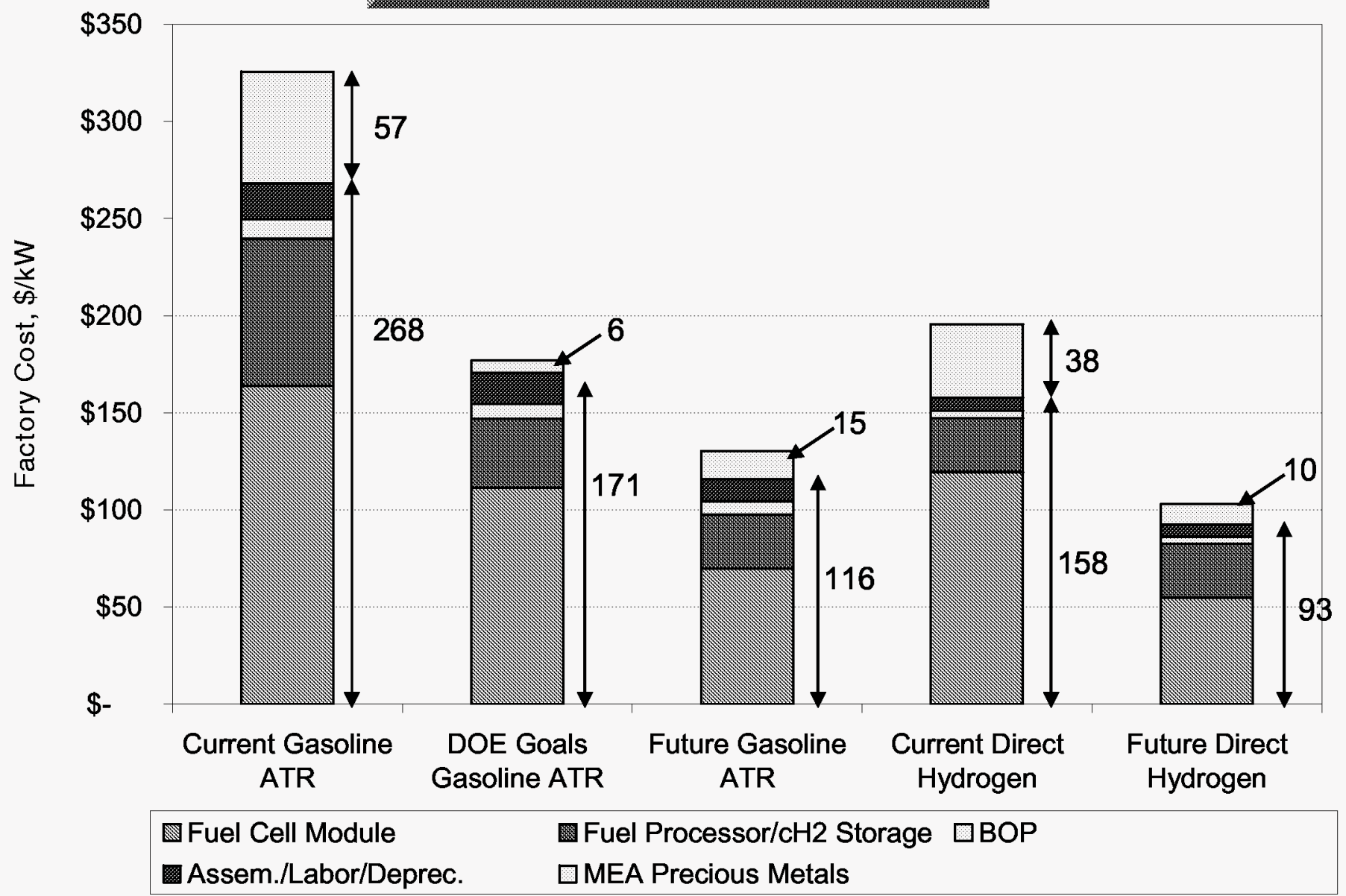

See Appendix pages $30-32$ for assumptions. 


\section{Project Overview Platinum Loading}

In both reformate and direct hydrogen cases, the minimum in stack material costs occurs around cathode platinum loadings of $0.2 \mathrm{mg} / \mathrm{cm}^{2}$.
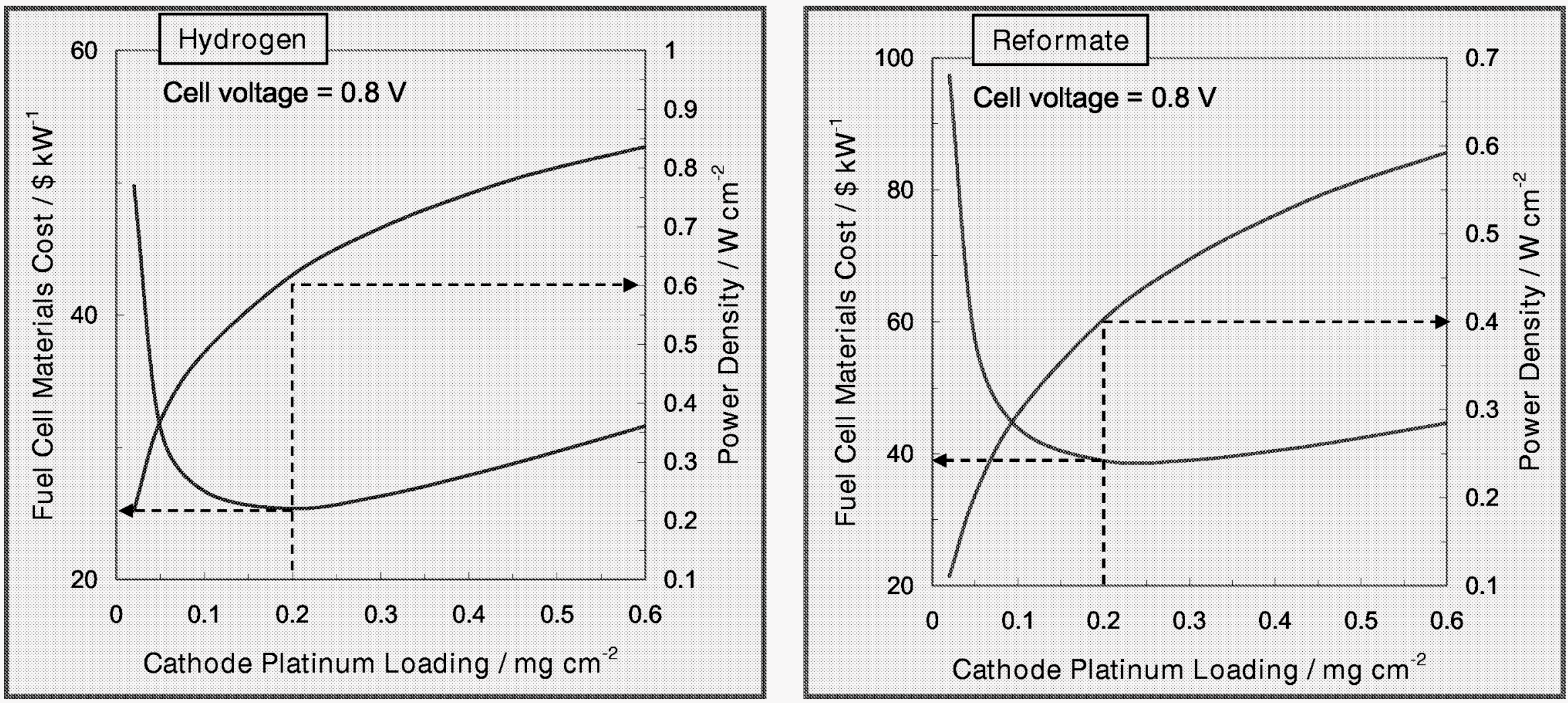

\begin{tabular}{|c|c|c|}
\hline 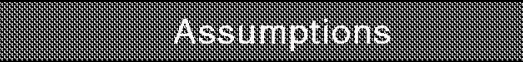 & y & 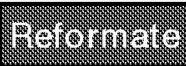 \\
\hline Anode overpotential (mV) & 0 & 30 \\
\hline Membrane Resistance $\left(\mathrm{m} \Omega \mathrm{cm}^{2}\right)$ & 50 & 50 \\
\hline Electronic Reisistance $\left(\mathrm{m} \Omega \mathrm{cm}^{2}\right)$ & 20 & 20 \\
\hline
\end{tabular}

Operating Conditions:

$0.8 \mathrm{~V}, 3 \mathrm{~atm}, 160 \mathrm{C}, 3.5 \mathrm{~nm}$ Particles, 2x Pt activity 


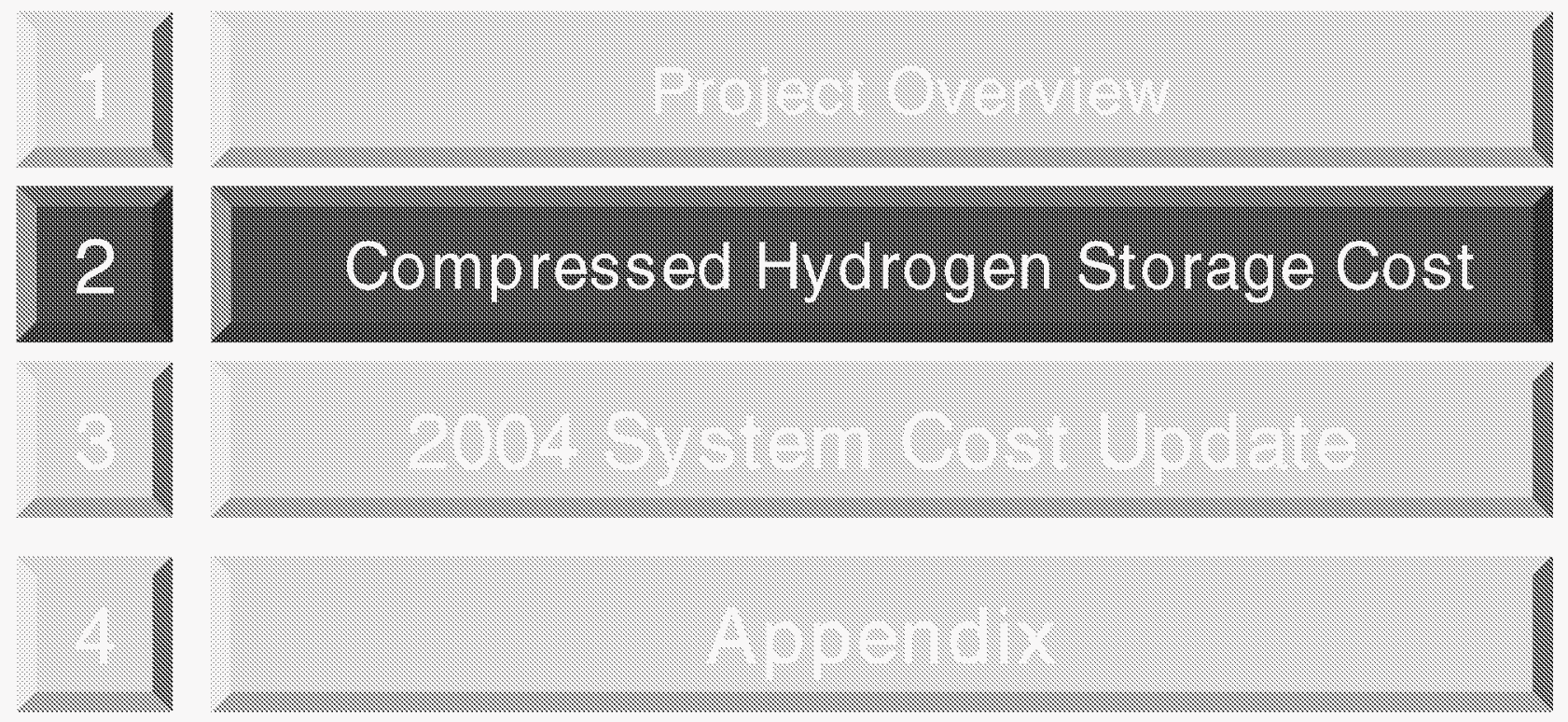


We worked with Argonne National Laboratories (ANL) to define the overall system and hydrogen requirements for a mid-size vehicle.

Process Water

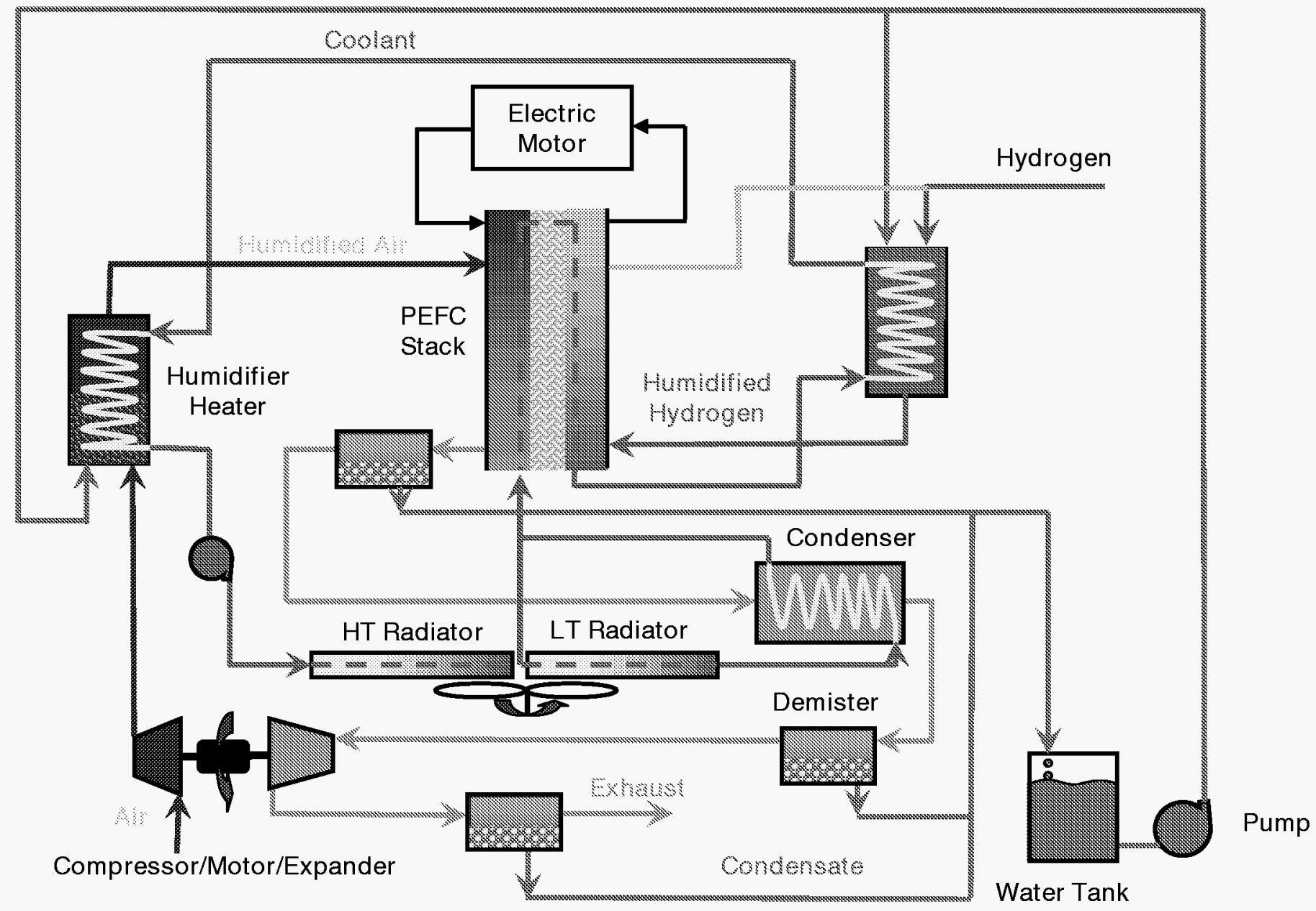

Source: Dr. Rajesh Ahluwalia of ANL 


\section{Compressed Hydrogen Storage Cost System Specification $\mathrm{H}_{2}$ Requirement}

Several hybridization scenarios were considered before choosing an $80 \mathrm{~kW}$ fuel cell with a "40kW" battery requiring $5.6 \mathrm{~kg}$ hydrogen storage.

\begin{tabular}{|l|c|c|c|c|c|c|}
\hline \multicolumn{1}{|c|}{ ANL Results } & $\begin{array}{c}\text { ICEV 120 } \\
\text { kW }\end{array}$ & $\begin{array}{c}\text { FC EV } \\
120\end{array}$ & $\begin{array}{c}\text { FC HEV } \\
100 \mathrm{~kW}\end{array}$ & $\begin{array}{c}\text { FC HEV } \\
80 \mathrm{~kW}\end{array}$ & $\begin{array}{c}\text { FC HEV } \\
60 \mathrm{~kW}\end{array}$ \\
\hline $\begin{array}{l}\text { Engine/Fuel Cell Power, } \\
\text { kW peak }\end{array}$ & 114 & 120 & 100 & 80 & 60 \\
\hline Battery Power, kW peak & 0 & 0 & 20 & 40 & 55 \\
\hline Fuel Economy, mpeg & 23 & 59 & 65 & 68 & 69 \\
\hline Hydrogen Required & NA & 6.3 & 5.9 & 5.6 & 5.6 \\
\hline
\end{tabular}

References: 1.) Ahluwalia, R.K. and Wang, X., "Direct Hydrogen Fuel Cell Systems for Hybrid Vehicles," Journal of Power Sources, In print, 2004; 2.) Ahluwalia, R.K., Wang, X. and Rousseau, A., "Fuel Economy of Hybrid Fuel Cell Vehicles," 2004 Fuel Cell Seminar, San Antonio, TX, Nov. 2-5, 2004.

The analysis was conducted for a mid-size vehicle with a 370 mile range on a combined urban/highway drive cycle. 


\section{We used the hydrogen storage system schematic below as a basis for the} cost assessment. *

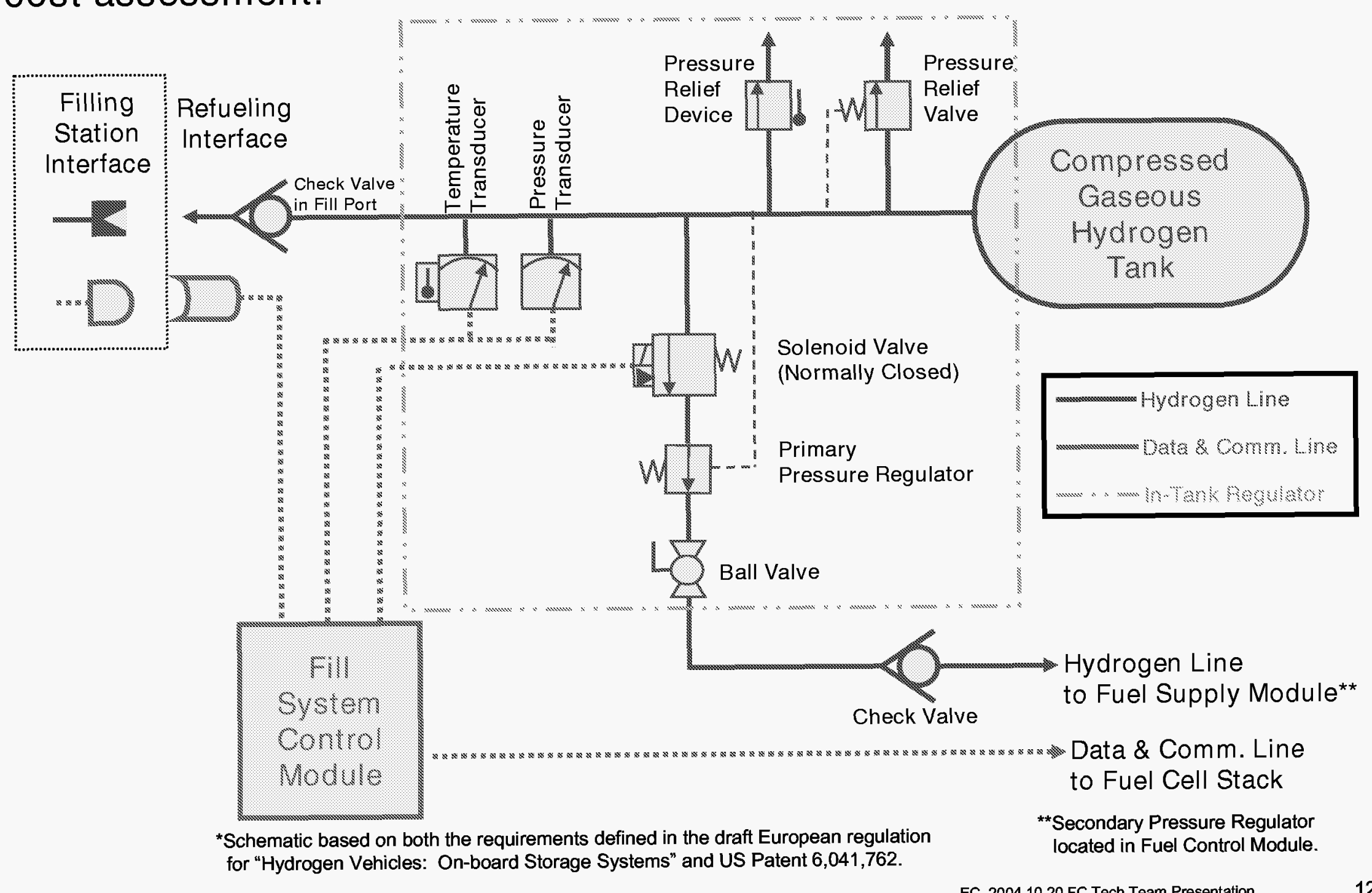


We used a typical Type III or Type IV tank as the basis for our costing effort.
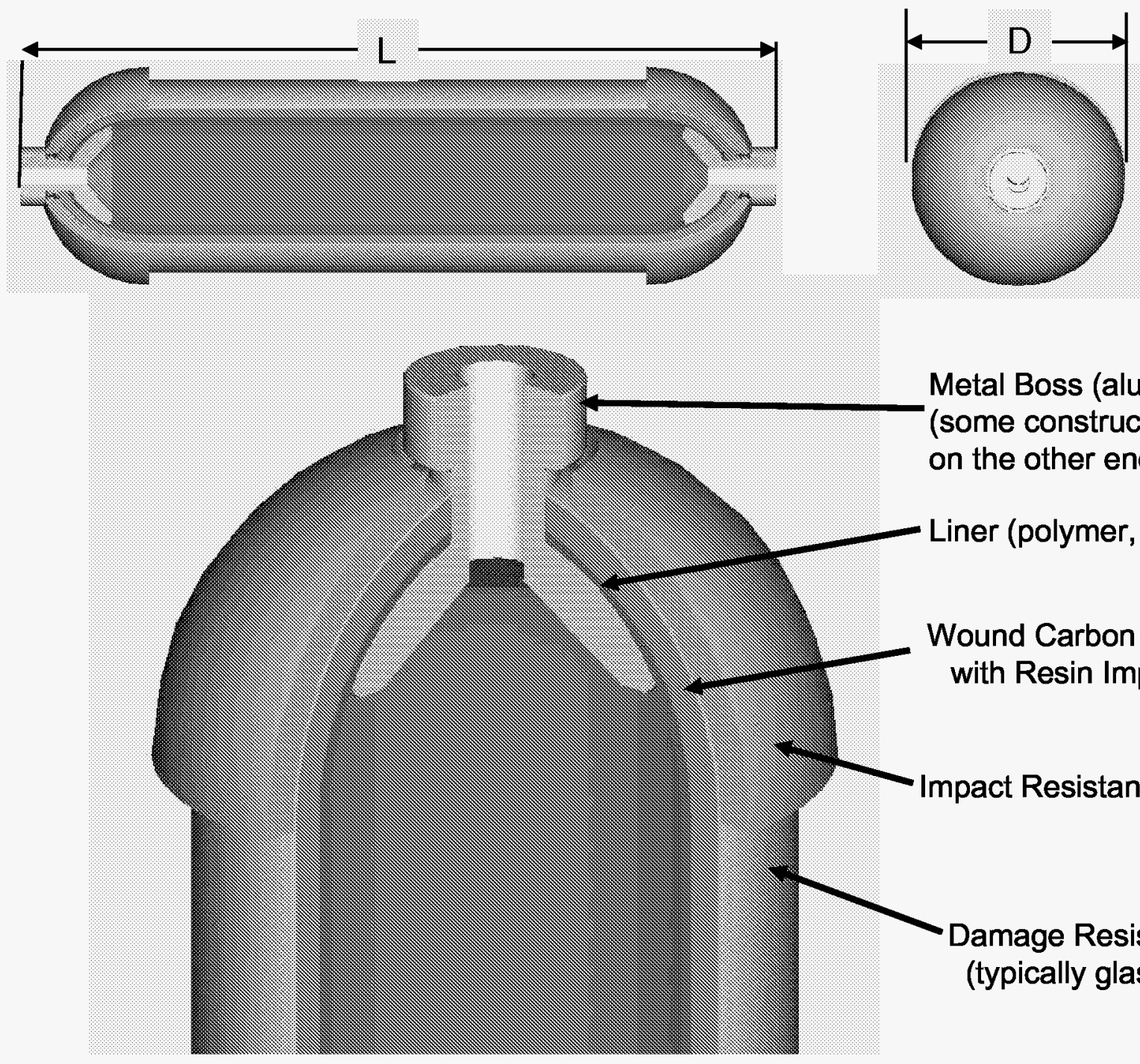

Metal Boss (aluminum) for Tank Access (some constructions may also use a plug on the other end)

Liner (polymer, metal, laminate)

Wound Carbon Fiber Structural Layer with Resin Impregnation

mpact Resistant Foam End Dome

Damage Resistant Outer Layer (typically glass fiber wound) 
The 5,000 and 10,000 psi Baseline systems have similar weight distributions with the carbon fiber layer being the largest contributor.

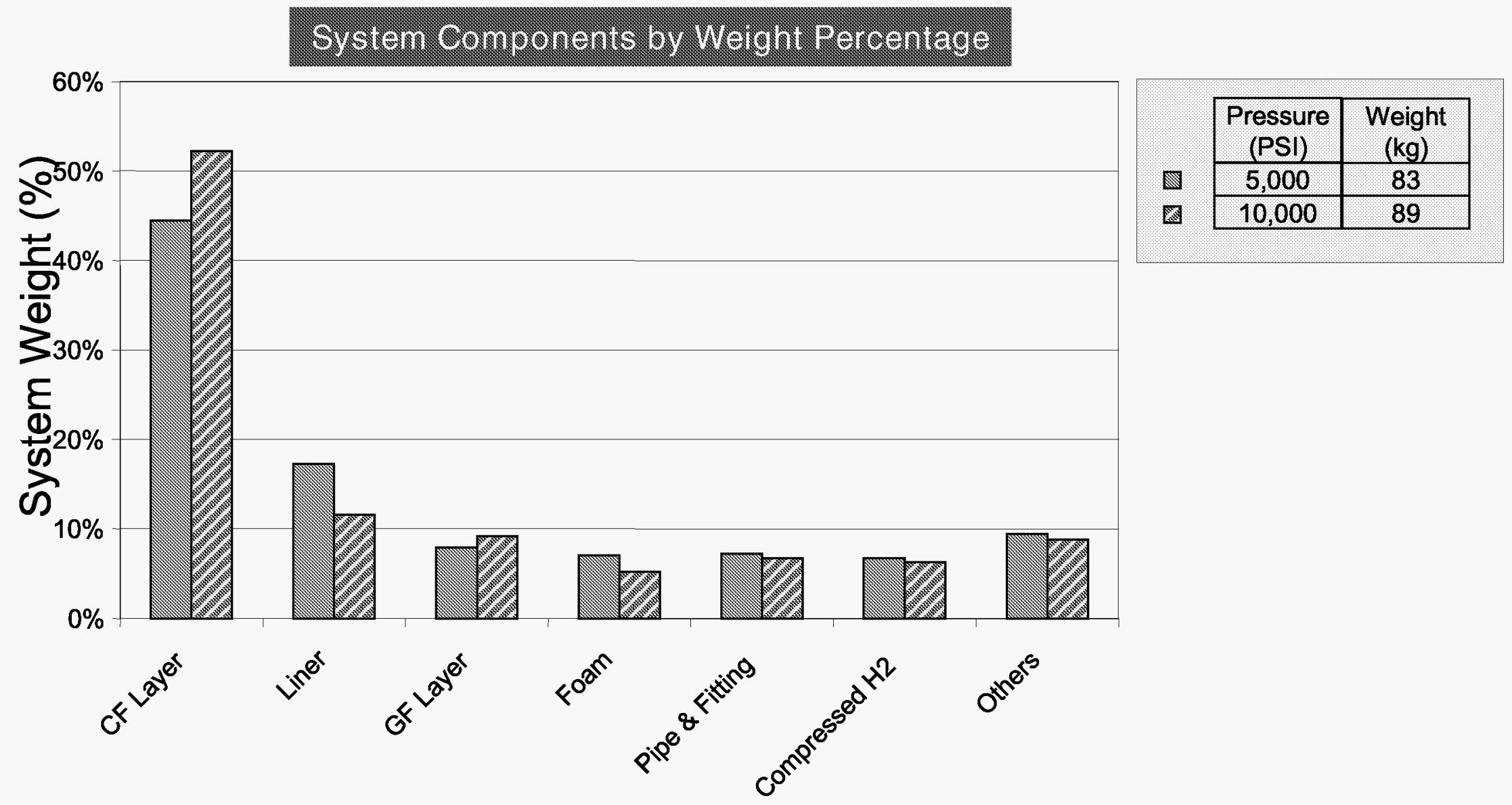

Other components (including regulator, fill port, sensors, valves, bosses, and packaging), each contribute less than $3 \%$. 
Storage system costs start at $10-15 \$ / \mathrm{kWh}$ and increase with the use of multiple tanks to improve the form factor and the use of higher strength carbon fiber for weight reduction.

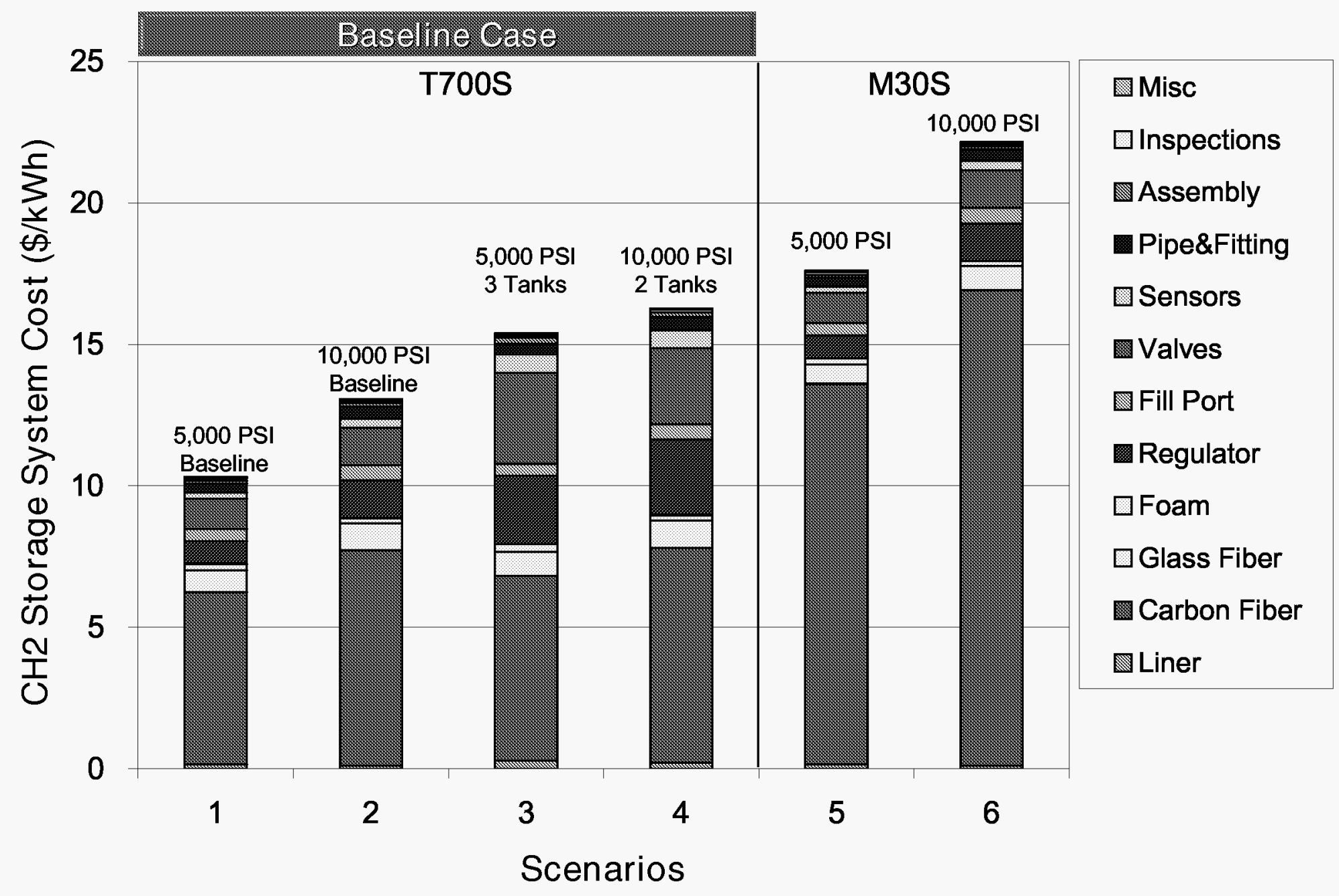


The 5,000 and 10,000 PSI Baseline systems have a similar distribution of cost. Carbon fiber is the dominant cost contributor by a large margin.

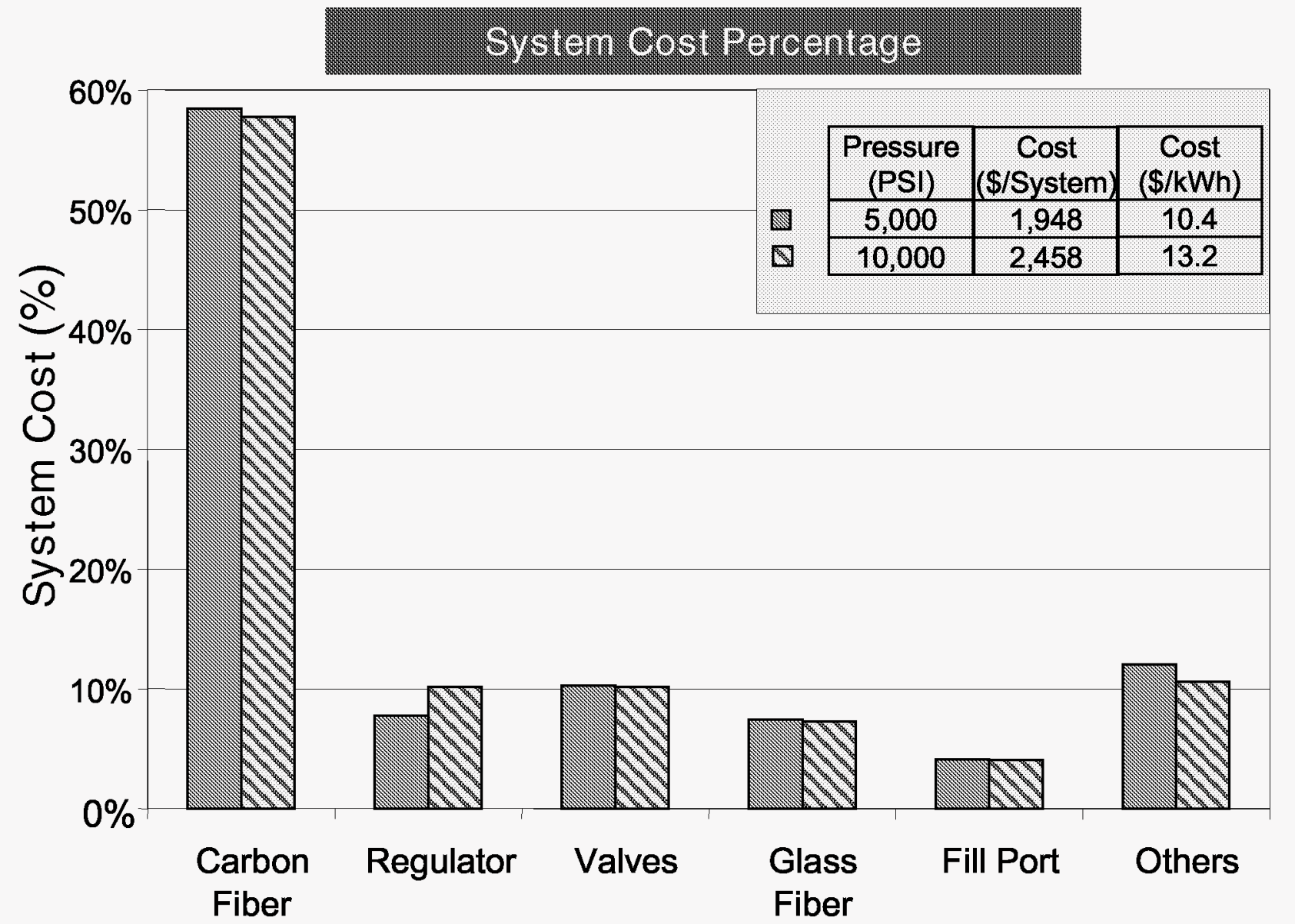

Other components, including the liner, foam, sensors, and bosses contribute less than $3 \%$ each to the total. 
Compressed Hydrogen Storage Cost Single Parameter Sensitivity Analysis Tank Cost

Overall system cost is dominated by the carbon fiber cost and weight. The other factors have much less impact on cost.

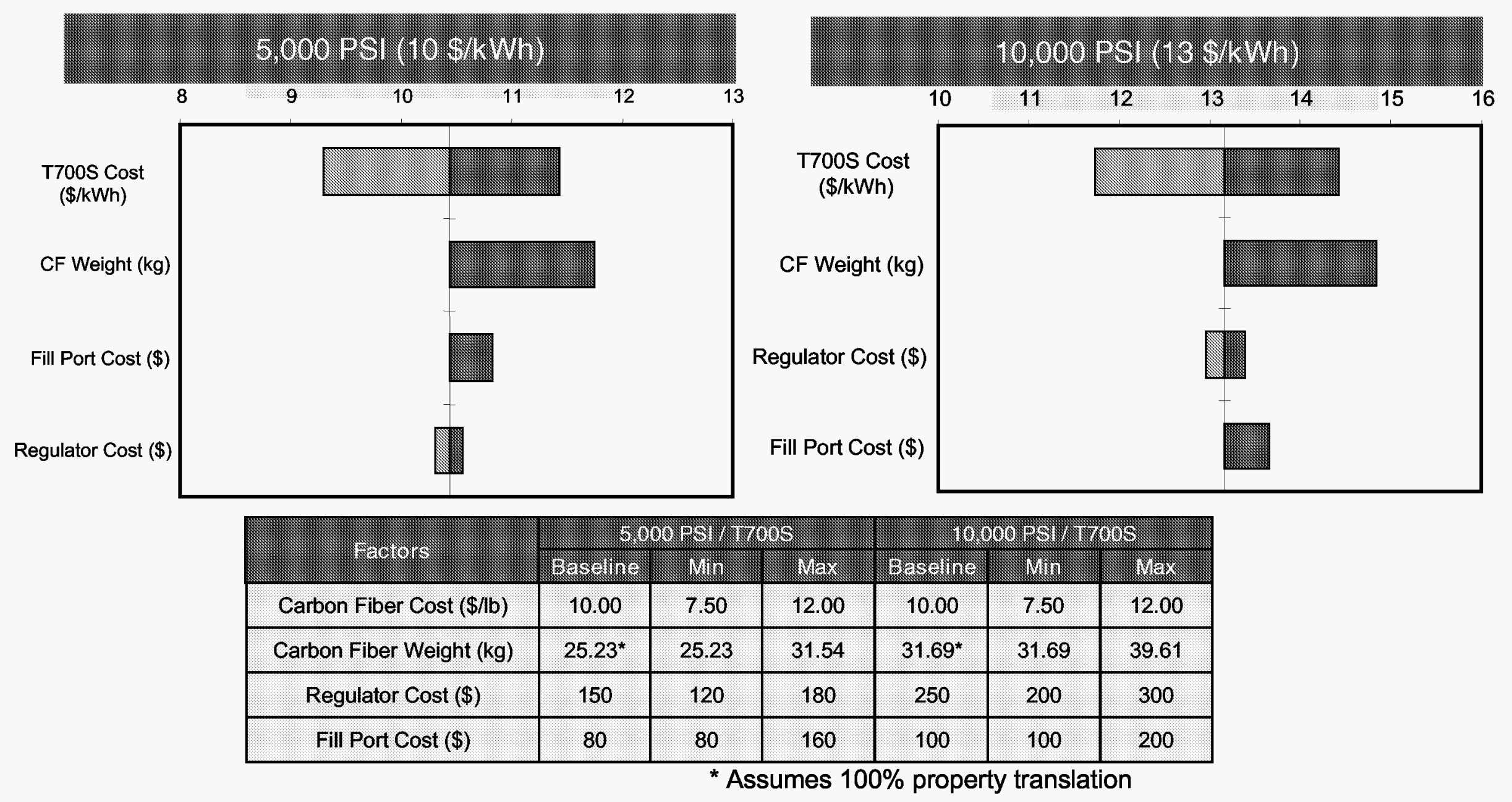


Compressed Hydrogen Storage Cost Model Results versus DOE System Goals

Our results indicate that compressed hydrogen will be 2-3 times more costly than the DOE near-term target.
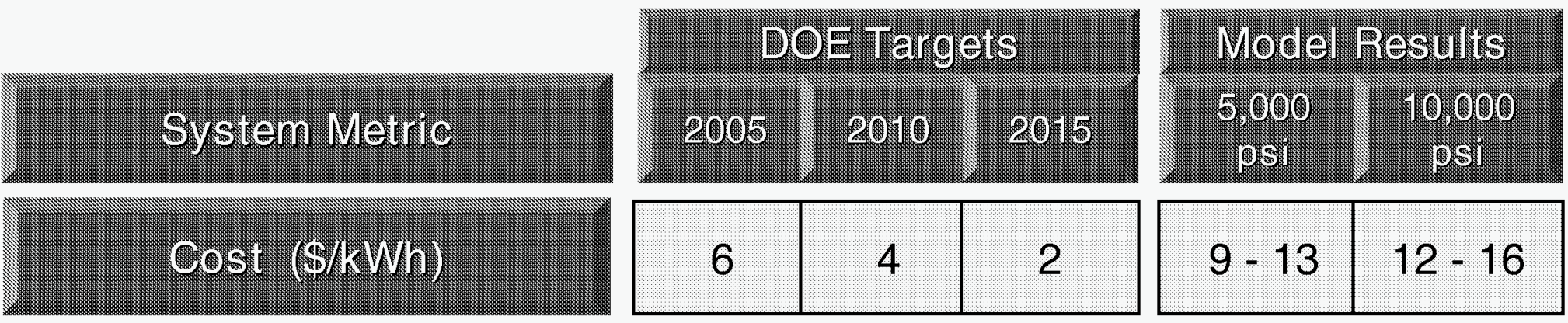

\begin{tabular}{|l|l|}
\hline $9-13$ & $12-16$ \\
\hline
\end{tabular}

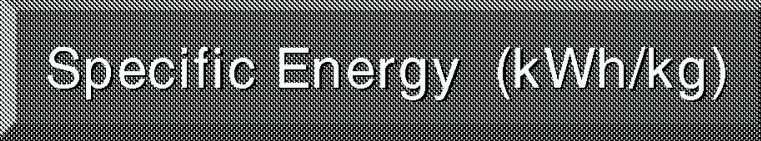

\begin{tabular}{|l|l|l|}
\hline 1.5 & 2 & 3 \\
\hline
\end{tabular}

\begin{tabular}{|l|l|}
\hline 2.2 & 2.1 \\
\hline
\end{tabular}

Energy Density (kWh/iter)

\begin{tabular}{|l|l|l|}
\hline 1.2 & 1.5 & 2.7 \\
\hline 4.5 & 6 & 9 \\
\hline
\end{tabular}

\begin{tabular}{|l|l|}
\hline $0.6^{*}$ & $0.9^{\star}$ \\
\hline 6.7 & 6.3 \\
\hline
\end{tabular}

* Tank only volume

On a volumetric basis, our model results for both 5,000 and 10,000 psi tanks projected volumes do not meet the DOE targets. 
Our findings indicate that it will be difficult to achieve the DOE targets for compressed hydrogen storage due to the required amount and cost of carbon fiber.

- Carbon Fiber Issues

- Aerospace grade carbon fibers must be used to achieve reliability, safety, and life

- Commercial grade fibers will not provide the mechanical properties or reliability required for this application

- Aerospace fibers are currently made in high volume and we do not anticipate much further cost reduction

- The system modeled in this assessment will meet mid-term specific energy target and will not be able to satisfy even the near-term volumetric energy density target. 


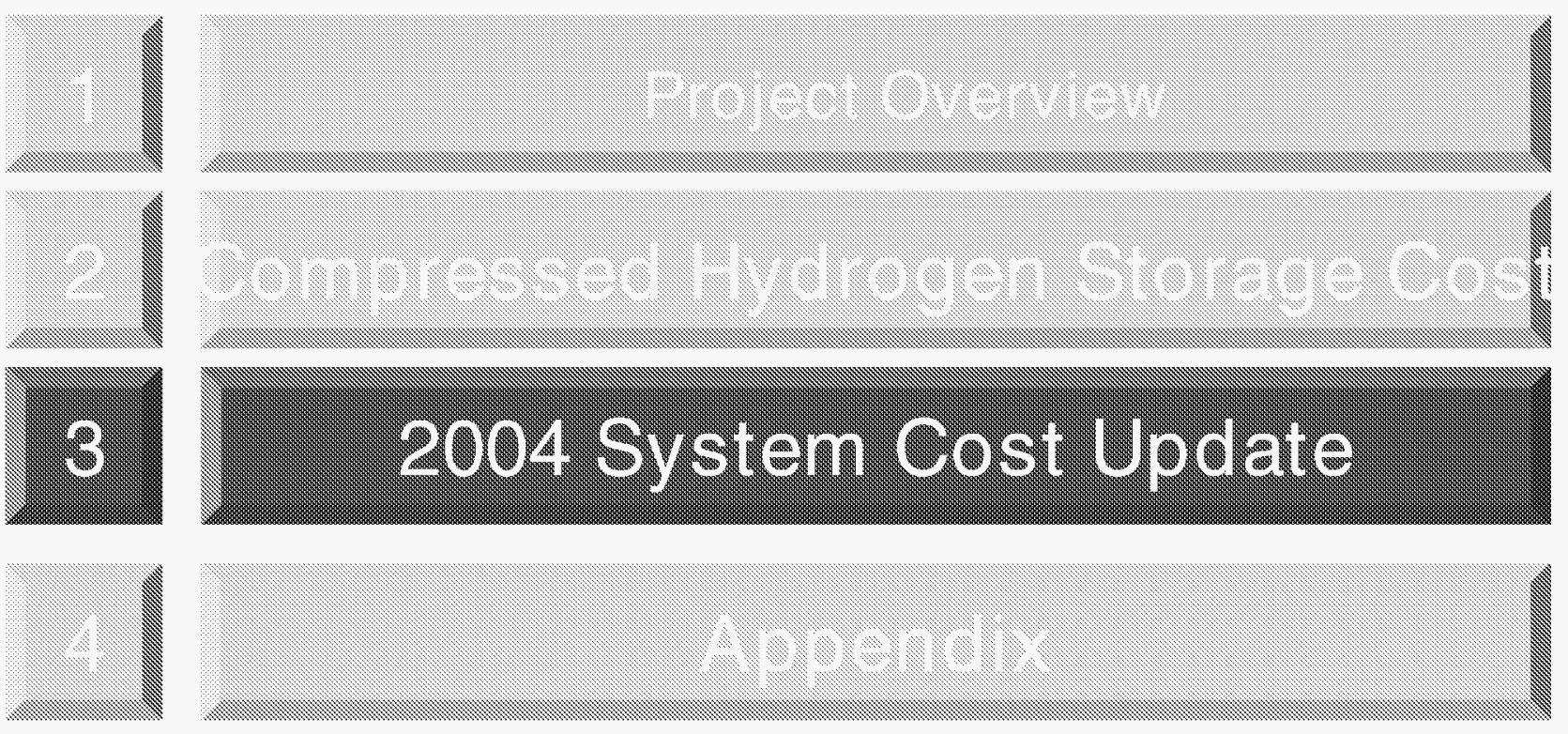


Our 2004 estimate of a $\mathrm{cH}_{2}$ fuel cell system with today's performance produced at high volume is $\$ 175 / \mathrm{kW}$.

Preliminary Results

\begin{tabular}{|c|c|c|c|c|}
\hline \multirow[b]{2}{*}{$\begin{array}{l}50 \text { kW Fuel Cell } \\
\text { System - Current } \\
\text { Technology }\end{array}$} & \multicolumn{2}{|c|}{2001 Estimate } & 2004 & 2004 \\
\hline & $\begin{array}{c}\text { Baseline } \\
\text { Refomate } \\
(\$ / \mathrm{kW})\end{array}$ & $\begin{array}{l}\text { Direct } \\
\mathrm{CH} 2 \\
(\$ / \mathrm{kW})\end{array}$ & $\begin{array}{c}\text { Direct } \\
\mathrm{CH} 2 \\
(\$ / \mathrm{kW})\end{array}$ & $\begin{array}{l}\text { Direct } \\
\mathrm{CH} 2 \\
(\$ / \mathrm{kW})\end{array}$ \\
\hline Fuel Cell & $\$ 221$ & $\$ 155$ & $\$ 104$ & $\$ 97$ \\
\hline Fuel Supply & $\$ 76$ & $\$ 29$ & $\$ 58$ & $\$ 38$ \\
\hline Balance of Plant & $\$ 10$ & $\$ 4$ & $\$ 5$ & $\$ 4$ \\
\hline Assembly \& Indirect & $\$ 17$ & $\$ 7$ & $\$ 8$ & $\$ 6$ \\
\hline Total $(\$ / \mathrm{kW})$ & $\$ 324$ & $\$ 195$ & $\$ 176$ & $\$ 145$ \\
\hline Total (\$) & $\$ 16,200$ & $\$ 9,750$ & $\$ 8,800$ & $\$ 11,600$ \\
\hline
\end{tabular}

- The 2004 cost estimate has a lower fuel cell subsystem cost but higher fuel supply (i.e., $\mathrm{cH}_{2}$ storage system) cost driven primarily by higher stack power density

- The $80 \mathrm{~kW}$ system reduces $\$ / \mathrm{kW}$ cost due to "economies of scale", but the absolute cost is higher

- Note that the $\mathrm{cH}_{2}$ storage system is assumed to be the same size and cost

- A complete powertrain cost analysis is needed to determine the net benefits 
The 2004 cost estimate had a lower stack cost due to higher power density and reduced membrane and Pt cost assumptions.

\begin{tabular}{|c|c|c|c|c|}
\hline \multirow{3}{*}{$\begin{array}{l}50 \text { kW Fuel Cell } \\
\text { Subsystem - } \\
\text { Current Technology }\end{array}$} & & & \multicolumn{2}{|c|}{ Preliminary Results } \\
\hline & \multicolumn{2}{|c|}{2001 Estimate } & 2004 & 2004 \\
\hline & $\begin{array}{c}\text { Baseline } \\
\text { Refomate } \\
(\$ / \mathrm{kW})\end{array}$ & $\begin{array}{l}\text { Direct } \\
\mathrm{CH} 2 \\
(\$ / \mathrm{kW})\end{array}$ & $\begin{array}{l}\text { Direct } \\
\mathrm{CH} 2 \\
(\$ / \mathrm{kW})\end{array}$ & $\begin{array}{l}\text { Direct } \\
\mathrm{CH} 2 \\
(\$ / \mathrm{kW})\end{array}$ \\
\hline Fuel Cell Stack & $\$ 181$ & $\$ 123$ & $\$ 73$ & $\$ 72$ \\
\hline Tailgas Burner & $\$ 7$ & $\$ 6$ & $\$ 0$ & $\$ 0$ \\
\hline Air Supply & $\$ 20$ & $\$ 15$ & $\$ 20$ & $\$ 13$ \\
\hline Cooling System & $\$ 12$ & $\$ 10$ & $\$ 11$ & $\$ 12$ \\
\hline Total $(\$ / \mathrm{kW})$ & $\$ 220$ & $\$ 155$ & $\$ 104$ & $\$ 97$ \\
\hline Total $(\$)$ & $\$ 10,988$ & $\$ 7,737$ & $\$ 5,215$ & $\$ 7,729$ \\
\hline
\end{tabular}

- Higher power density is based on lower cell voltage operation despite having a reduced Pt loading compared to 2001

- Note that a tailgas burner was not part of the ANL fuel cell system design in 2004 
The fuel cell stack makes up a majority of the total cost for the $80 \mathrm{~kW}$ Direct Hydrogen Fuel Cell System.
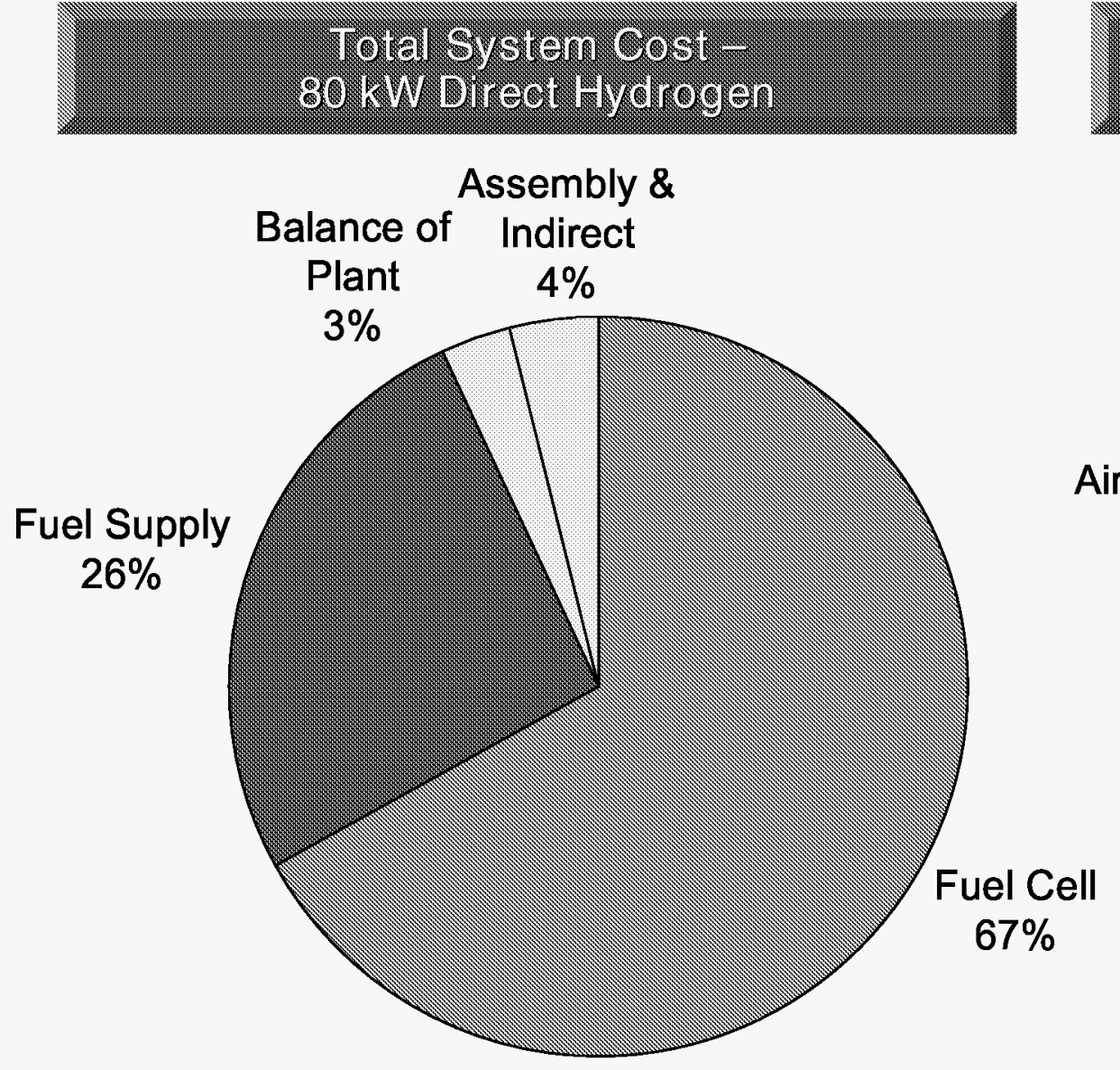

Preliminary Results

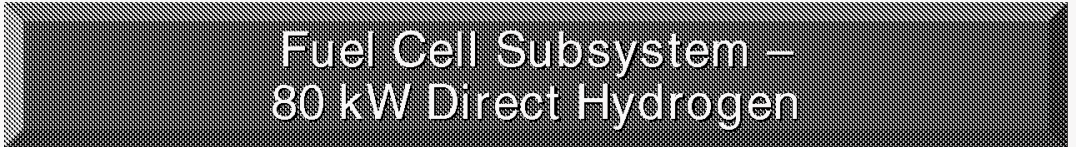

Cooling

System

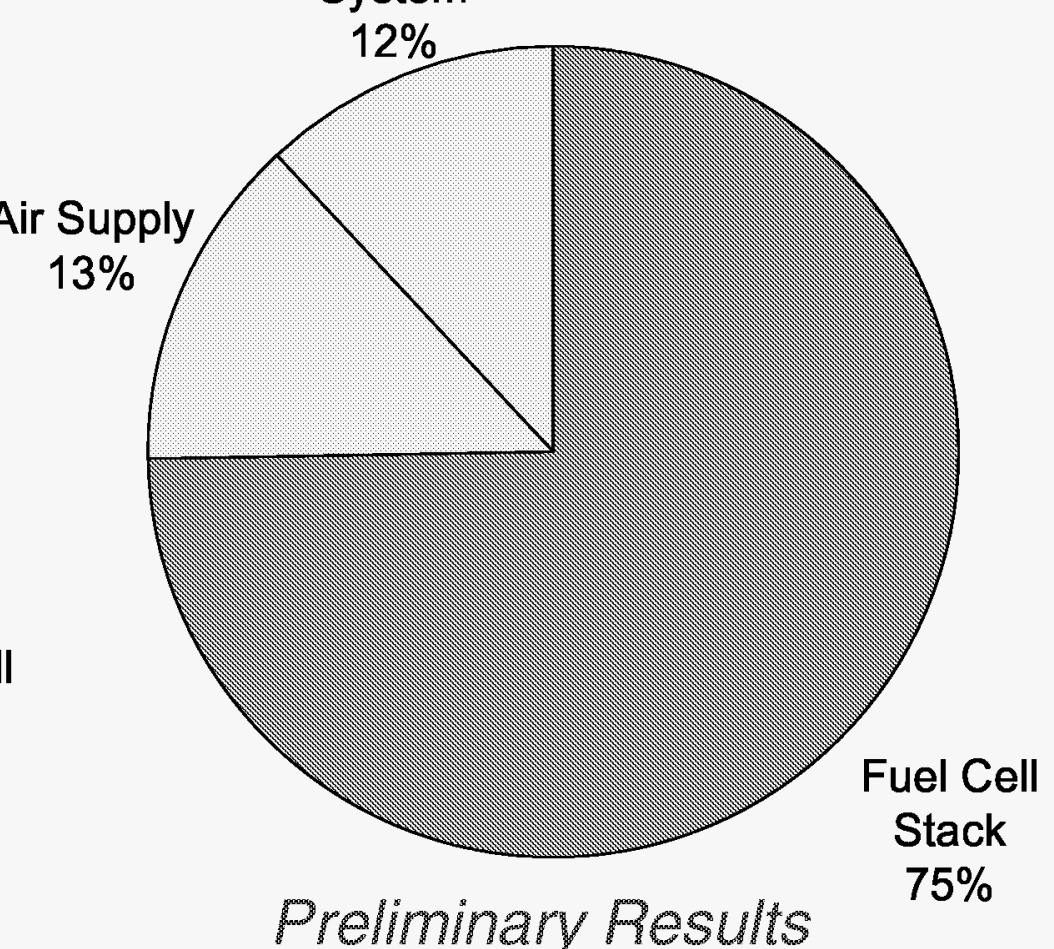


The membrane and electrodes make up over half of the $\$ 72 / \mathrm{kW}$ fuel cell stack cost.

Fuel Cell Stack Cost - 80 kW Direct Hydrogen

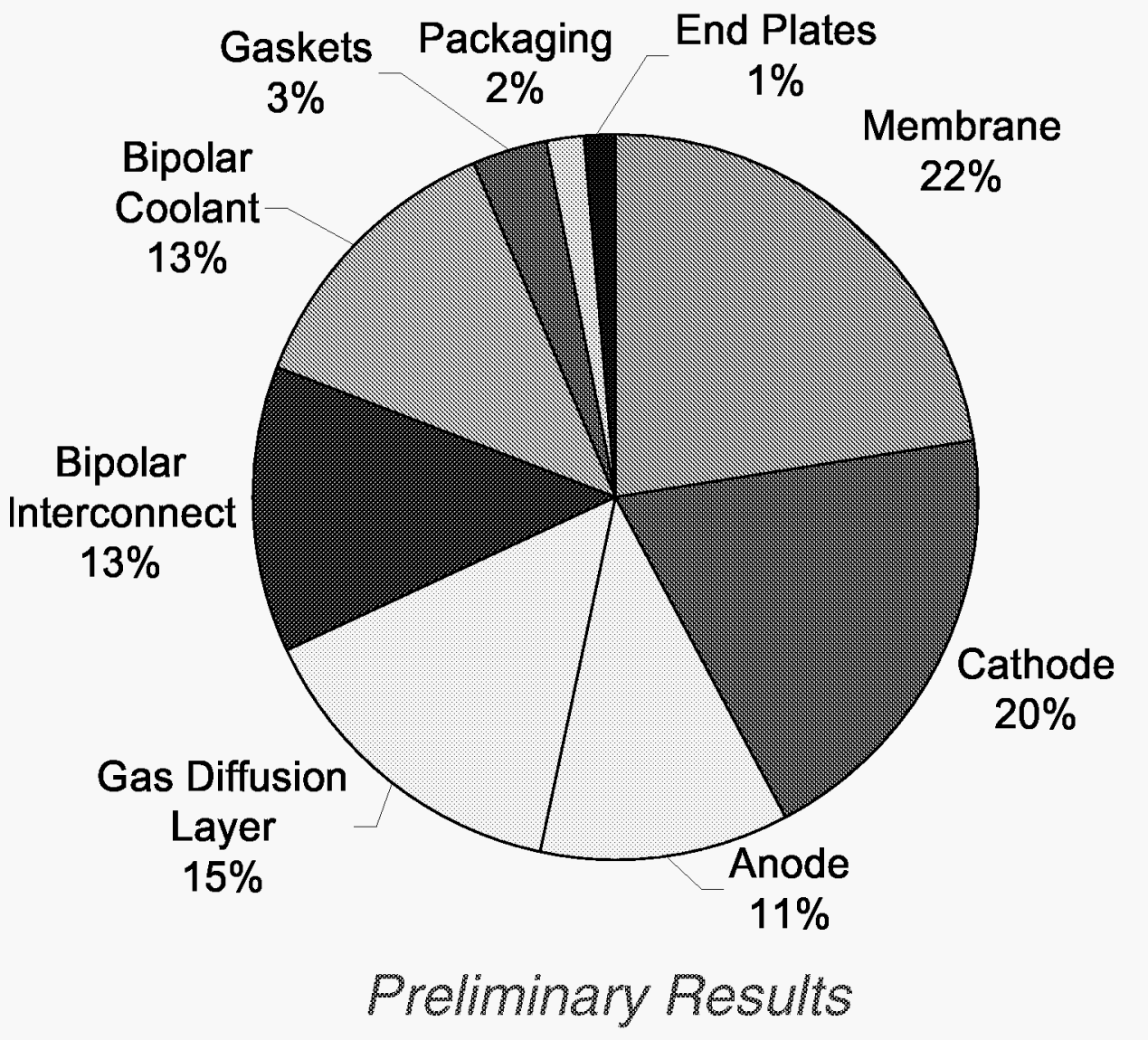


- The $80 \mathrm{~kW}$ system cost projection includes assumptions more representative of a vehicle, including

- a mid-size vehicle platform and a hybrid powertrain

- Uses drive cycle analysis and a 370 mile range to calculate efficiency and hydrogen requirements rather than calculating efficiency at rated power

- Cost is still significantly higher than DOE targets

- Need to clarify basis of cost comparison with targets and ICE powertrains

- Powertrain cost in dollars $(\$ 11,600)$ for a mid-size hybrid vehicle provides unambiguous metric

- Stack cost still represents $50 \%$ of the system cost 


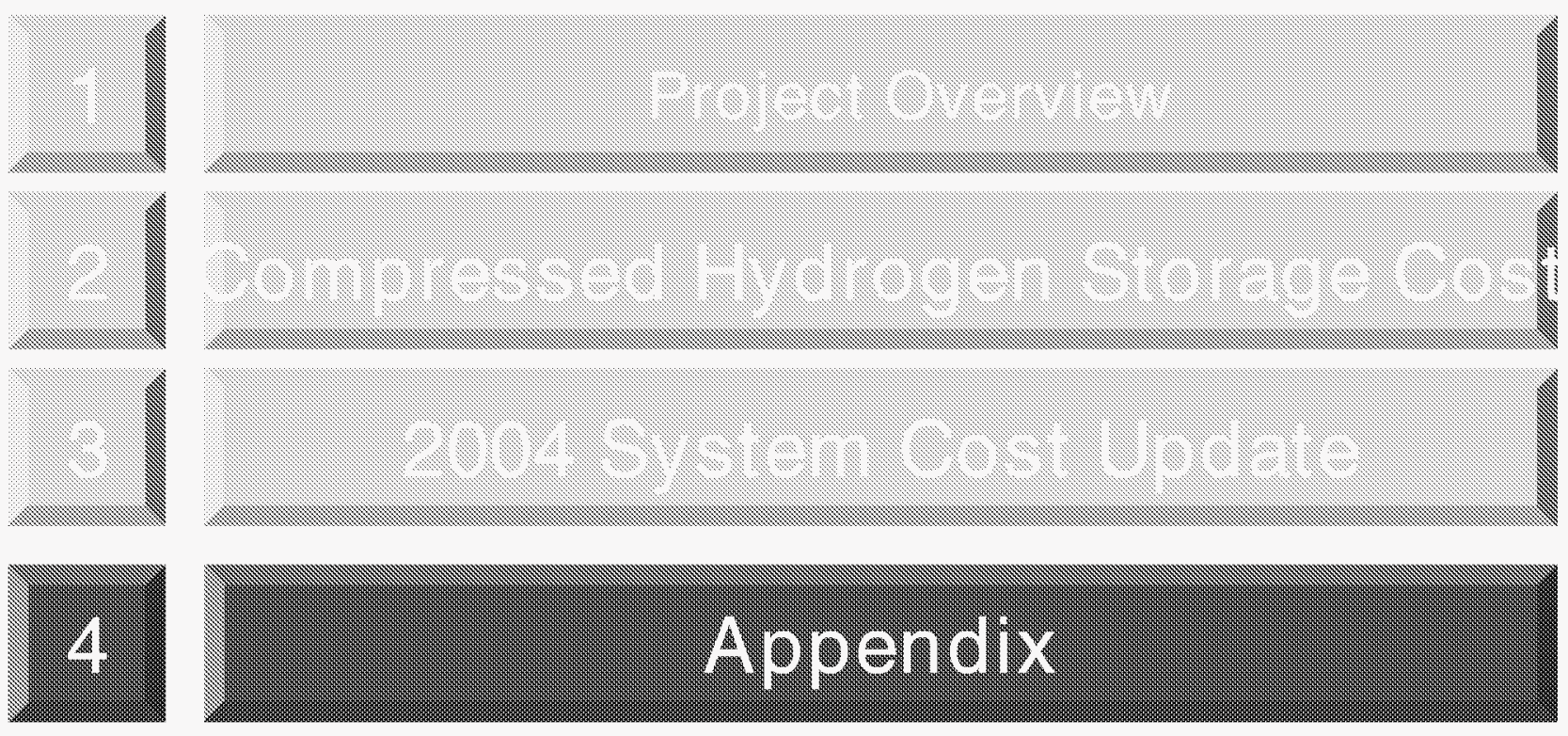




\section{Program Overview Project Team}

In the initial tasks of the project, Argonne National Laboratory provided modeling support.

Program Manager: Nancy Garland

ANL Technical Advisor: Robert Sutton

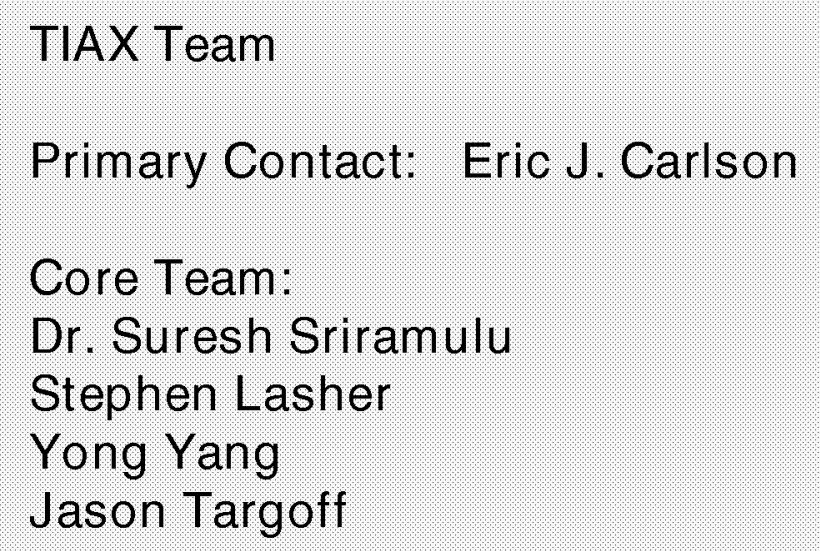

\author{
Argonne National Laboratory \\ System Modeling \\ Primary Contacts: Dr. Romesh Kumar \\ Dr. Rajesh Ahluwalia
}




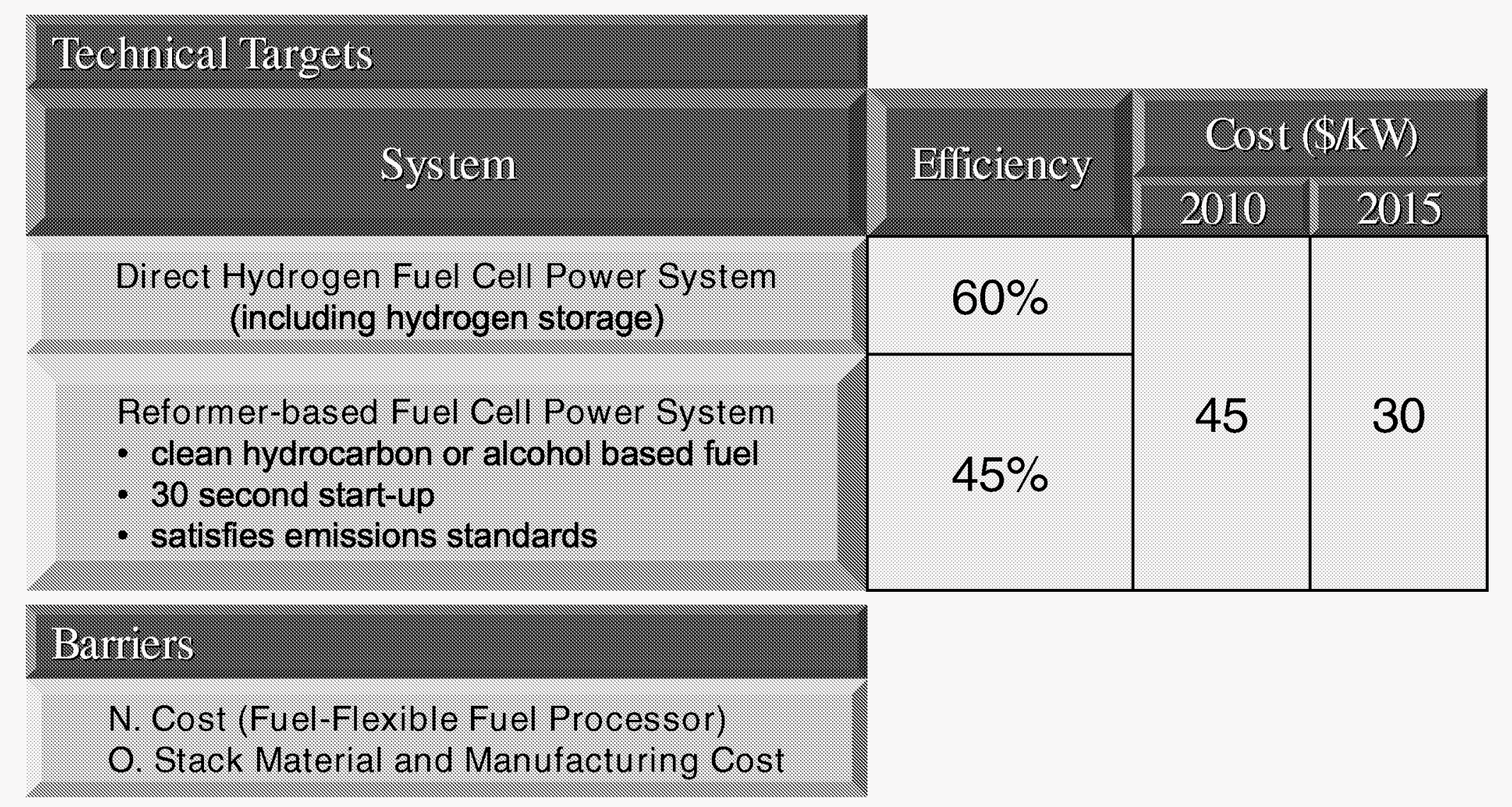




\begin{tabular}{|c|c|c|c|c|c|}
\hline \multicolumn{3}{|c|}{ Technical Targets } & 2005 & 2010 & 2015 \\
\hline \multicolumn{6}{|c|}{ Direct Hydrogen Fuel Cell Power System } \\
\hline \multirow{2}{*}{$\begin{array}{c}\text { Systen } \\
\text { Level } \\
\end{array}$} & Efficiency & $\%$ & \multicolumn{3}{|c|}{$60 \%$} \\
\hline & Cost & $\$ / k W$ & & 45 & 30 \\
\hline \multirow{7}{*}{$\mathrm{H}_{2}$ Storage } & \multirow{2}{*}{$\begin{array}{l}\text { Specific Energy } \\
\text { Density }\end{array}$} & $\mathrm{kWh} / \mathrm{kg}$ & 1.5 & 2 & 3 \\
\hline & & $\%$ & 4.5 & 6 & 9 \\
\hline & Energy Density & $\mathrm{kWh} / \mathrm{L}$ & 1.2 & 1.5 & 2.7 \\
\hline & Cost & $\$ / \mathrm{kWh}$ & 6 & 4 & 2 \\
\hline & Refueling Rate & $\mathrm{kgH}_{2} / \mathrm{min}$ & 0.5 & 1.5 & 2 \\
\hline & $\mathrm{H}_{2}$ Losses & $(\mathrm{g} / \mathrm{hr}) / \mathrm{kg} \mathrm{H}$ & 1.0 & 0.1 & 0.05 \\
\hline & Min Flow Rate & $\mathrm{g} / \mathrm{sec} / \mathrm{kW}$ & 0.02 & 0.02 & 0.02 \\
\hline
\end{tabular}

Source: FreedomCAR Technical Targets: On-Board Hydrogen Storage Systems 
Appendix Future Scenarios Fuel Processor Precious Metals Breakout

The future reformate scenario replaces the ATR and LTS catalysts with more costly but more effective catalysts.

\begin{tabular}{|c|c|c|c|}
\hline $\begin{array}{l}\text { Precious Metal Content } \\
\text { and GHSV }\end{array}$ & $\begin{array}{l}\text { Current } \\
\text { Reformate }\end{array}$ & $\begin{array}{l}\text { DOE Goals } \\
\text { Reformate }\end{array}$ & $\begin{array}{l}\text { Future } \\
\text { Reformate }\end{array}$ \\
\hline ATR Platinum, g & 6.3 & 1.7 & 0 \\
\hline ATR Rhodium, g & 0 & 0 & 1.5 \\
\hline ATR GHSV, hr-1 & 80,000 & 200,000 & $1 \mathrm{MM}$ \\
\hline LTS Platinum, g & 0 & 0 & 6.3 \\
\hline LTS GHSV, hr-1 & 5,000 & 30,000 & 80,000 \\
\hline PrOX Platinum, $g$ & 7.1 & 1 & NA \\
\hline PrOX GHSV, hr-1 & 10,000 & 150,000 & NA \\
\hline
\end{tabular}

${ }^{*} \mathrm{Pt}=\$ 15 / \mathrm{g}, \mathrm{Rh}=\$ 30 / \mathrm{g}, \mathrm{Ru}=\$ 1.60 / \mathrm{g}$.

GHSV = gas hourly space velocity, calculated at standard temperature and pressure of the products. 
Appendix Future Scenarios MEA Precious Metals Breakout

The platinum content for the DOE Goals scenario is much lower than the other cases due to its very aggressive cathode loading assumption.

\begin{tabular}{|c|c|c|c|c|c|}
\hline $\begin{array}{l}\text { YE } \text { - Precious Metal } \\
\text { Calculation }\end{array}$ & $\begin{array}{l}2001 \\
\text { Petormate }\end{array}$ & $\begin{array}{l}\text { DOE Coals } \\
\text { Reformate }\end{array}$ & $\begin{array}{l}\text { Future } \\
\text { Peformate }\end{array}$ & $\begin{array}{l}2001 \\
\text { ivirogen: }\end{array}$ & $\begin{array}{l}\text { Future } \\
\text { indrogen }\end{array}$ \\
\hline Current Density & 310 & 400 & 500 & 405 & 750 \\
\hline $\begin{array}{l}\text { Cathode Pt Loading, } \\
\mathrm{mg} / \mathrm{cm}^{2}\end{array}$ & 0.4 & 0.05 & 0.2 & 0.4 & 0.2 \\
\hline $\begin{array}{l}\text { Anode Pt Loading, } \\
\mathrm{mg} / \mathrm{cm}^{2}\end{array}$ & 0.4 & 0.025 & 0.1 & 0.4 & 0.1 \\
\hline $\begin{array}{l}\text { Power Density, } \\
\mathrm{mW} / \mathrm{cm}^{2}\end{array}$ & 248 & 320 & 400 & 372 & 600 \\
\hline $\begin{array}{l}\text { Gross System } \\
\text { Power, kW }\end{array}$ & 56 & 56 & 53 & 56 & 53 \\
\hline Cathode Pt, g & 90 & 8.8 & 26 & 60 & 18 \\
\hline Anode Pt, g & 90 & 4.4 & 13 & 60 & 8.8 \\
\hline Anode Ru, g & 45 & 2.2 & 6.6 & 0 & 0 \\
\hline $\begin{array}{l}\text { Total Precious } \\
\text { Metals, } g\end{array}$ & 225 & 15 & 46 & 120 & 27 \\
\hline
\end{tabular}

${ }^{*} \mathrm{Pt}=\$ 15 / \mathrm{g}, \mathrm{Rh}=\$ 30 / \mathrm{g}, \mathrm{Ru}=\$ 1.60 / \mathrm{g}$. 
Only the future hydrogen scenario was able to meet the mid-term DOE cost targets outlined in the recent RFP.

\begin{tabular}{|c|c|c|c|c|c|c|c|}
\hline Characteristic & Enits: & $\begin{array}{l}\text { Mid- term } \\
\text { PNGV } \\
\text { Target }\end{array}$ & $\begin{array}{l}\text { DOE Goals } \\
\text { Peformate }\end{array}$ & $\begin{array}{l}\text { Euture } \\
\text { Petornate }\end{array}$ & $\begin{array}{l}\text { Long-term } \\
\text { PNGV } \\
\text { Target }\end{array}$ & $\begin{array}{l}\text { Current } \\
\text { rygrogen }\end{array}$ & $\begin{array}{l}\text { Future } \\
\text { Eydrogen }\end{array}$ \\
\hline $\begin{array}{l}\text { Overall System } \\
\text { Cost }^{1}\end{array}$ & $\$ / k W$ & 125 & 179 & 154 & 45 & 196 & 118 \\
\hline $\begin{array}{l}\text { Overall System } \\
\text { Specific Power' }\end{array}$ & W/kg & 250 & 181 & 291 & 325 & 165 & 365 \\
\hline Stack Cost ${ }^{2}$ & $\$ / k W$ & 100 & 120 & 108 & 35 & 157 & 81 \\
\hline $\begin{array}{l}\text { Stack Specific } \\
\text { Power }^{2}\end{array}$ & W/kg & 400 & 287 & 510 & 550 & 213 & 658 \\
\hline $\begin{array}{l}\text { Fuel Processor } \\
\text { Cost }^{3}\end{array}$ & $\$ / k W$ & 25 & 35 & 28 & 10 & NA & NA \\
\hline $\begin{array}{l}\text { Fuel Processor } \\
\text { Specific Power }^{3}\end{array}$ & W/kg & 700 & 694 & 1,250 & 800 & NA & NA \\
\hline
\end{tabular}

* Targets are based on DOE's Nov. 21, 2000 SFAA No. DE-RP04-01AL67057.

${ }^{1}$ Includes fuel processor or compressed hydrogen tank, stack, auxiliaries and startup devices; excludes fuel, gasoline tank, and vehicle traction electronics.

2 Includes fuel cell ancillaries: heat, water, air management systems; excludes fuel processing/delivery system.

${ }^{3}$ Excludes fuel storage; includes controls, shift reactors, $\mathrm{CO}$ cleanup, and heat exchanges. 
ANL performed vehicle drive cycle analyses based on a mid-sized family sedan with various degrees of hybridization.

- Vehicle Specifications

- Type

- Drag coefficient

- Frontal area

- Rolling resistance coefficient

- Vehicle mass (conventional)

- Engine power (conventional)

- Engine type (conventional)

- Transmission type (conventional)

- Performance Specifications

- Range

- Top speed (sustained)

- Response time

- Hill climb
Mid-sized sedan (e.g., Taurus)

0.33

$2 \mathrm{~m}^{2}$

0.009

$1557 \mathrm{~kg}$

$114 \mathrm{~kW}(155 \mathrm{hp})$

3L V6 - OHC

Automatic (2.7 / $1.5 / 1.0 / 0.7)$

370 miles on combined drive cycle $100 \mathrm{mph}$

0-60 mph in $10 \mathrm{sec}$ (with battery) $55 \mathrm{mph}$ at $6.5 \%$ grade for $20 \mathrm{~min}$ 
The ANL analyses sized the fuel cell, hydrogen, and battery systems to meet vehicle performance specifications.

- Fuel Cell System Specifications

- Power rating

- Efficiency

- Cathode utilization

- Transient response

- Start-up

- Cold start

- Water balance to meet top speed and hill climb spec. $50 \%$ LHV at rated power (DOE spec.) $50 \%$ (sustained) $1 \mathrm{sec}$ for 10 to $90 \%$ power max power in $15 \mathrm{sec}$ at $20^{\circ} \mathrm{C}$ max power in $30 \mathrm{sec}$ at $-20^{\circ} \mathrm{C}$ water self-sufficient up to $42^{\circ} \mathrm{C}$

- Hydrogen Storage Specifications

- Capacity

- Pressure sized to meet vehicle range spec. 350 and 700 bar $(5,000 / 10,000$ psi) 


\section{Appendix System Model Results Fuel Economy on Drive Cycles}

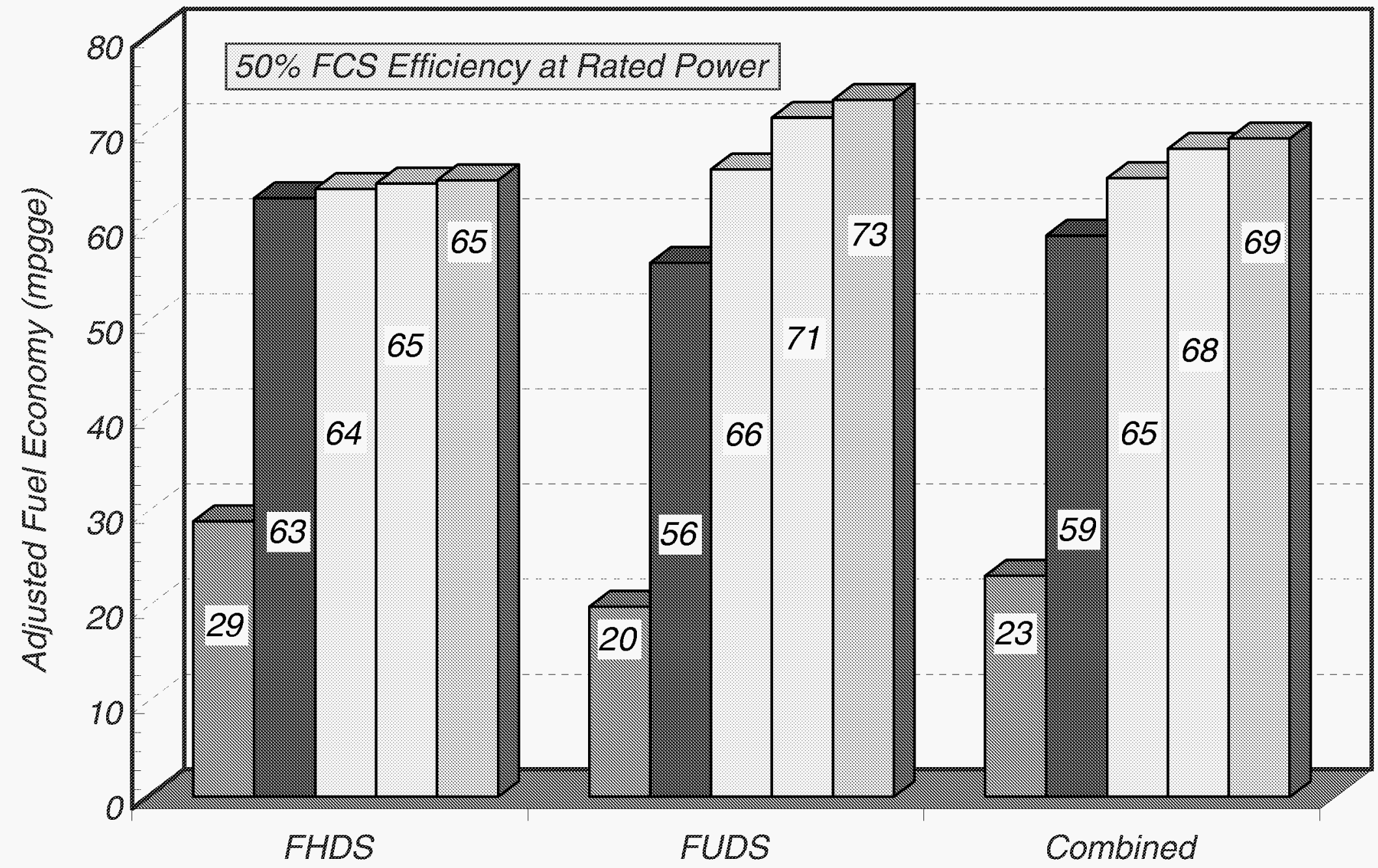

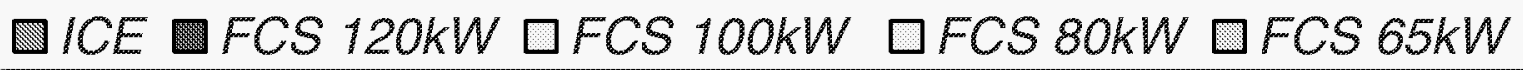

Source: ANL 
Appendix System Modeling Results Efficiencies on FUDS Cycle

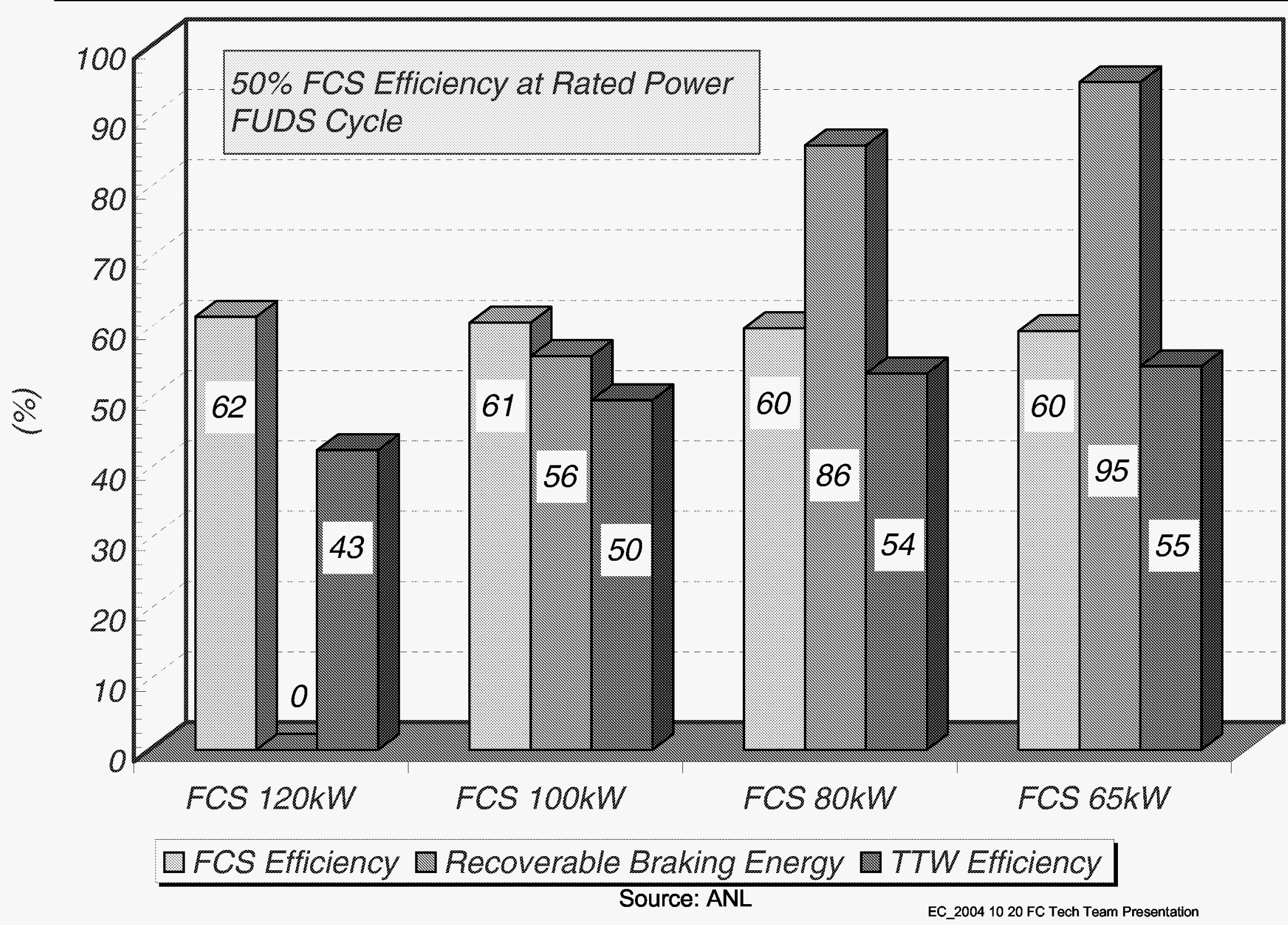




\section{Appendix System Modeling Results Effect of Turn Down on Cell Voltage and FCS Efficiency}

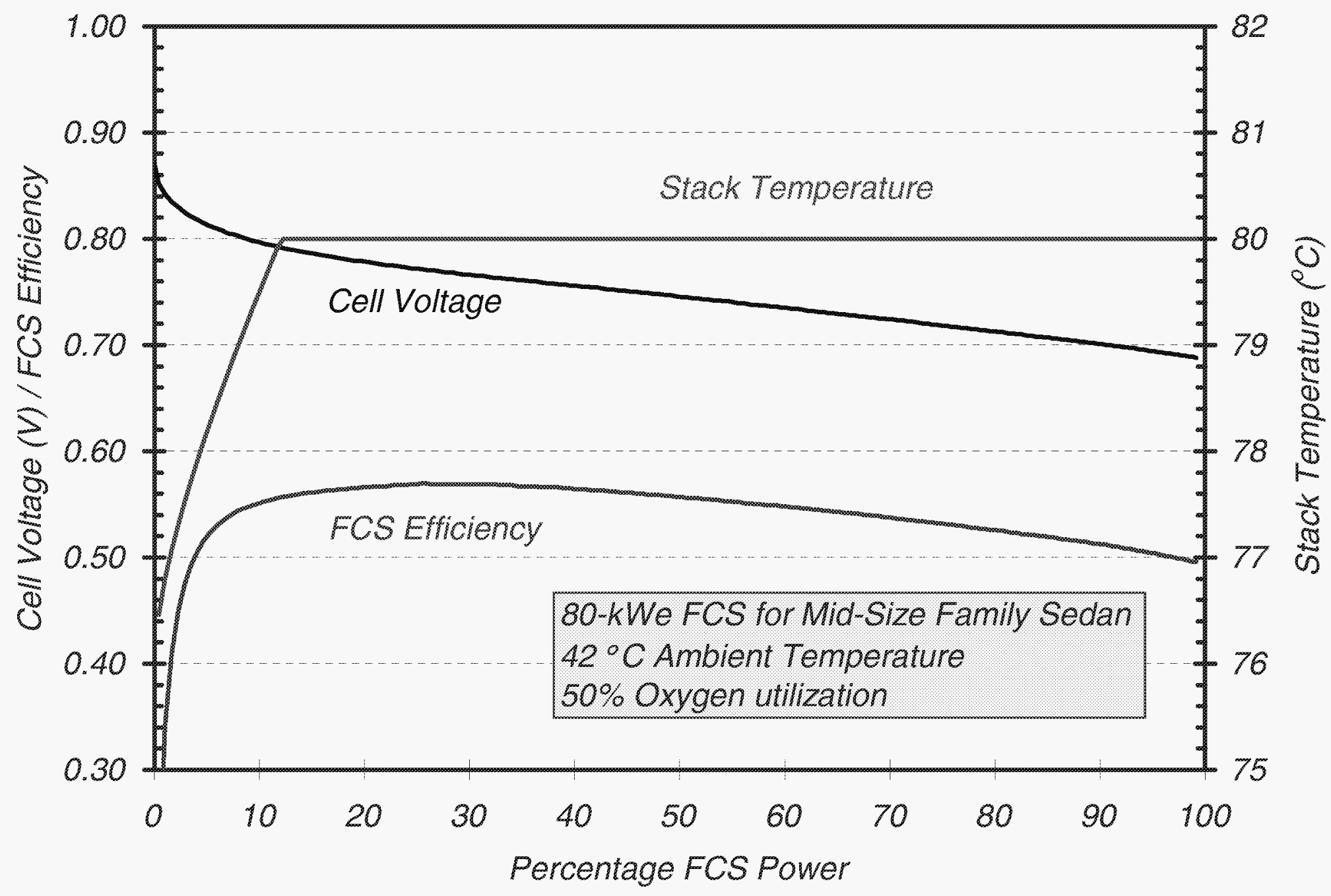

Source: ANL 
Appendix Hydrogen Tank Baseline Assumptions

For the baseline cases, we used a Toray T700S like carbon fiber and S-glass for the impact resistant outer layer.

\begin{tabular}{|c|c|c|}
\hline Parameters: & 5.c00 PSt Easeline & 10,000 PSI Easeline \\
\hline Production Volume (System /Year): & \multicolumn{2}{|c|}{500,000} \\
\hline Working Pressure (PSI) & 5,000 & 10,000 \\
\hline Total $\mathrm{H}_{2}$ storage Weight $(\mathrm{kg})^{\star}$ & 5.89 & 5.96 \\
\hline Tank Volume (liter) & 255 & 155 \\
\hline Tank Weight (kg) & 64 & 70 \\
\hline Liner Thickness \& Material & \multicolumn{2}{|c|}{0.25 Inch HDPE or 0.090 Inch Aluminum } \\
\hline Carbon Fiber Type & \multicolumn{2}{|c|}{ T700S } \\
\hline Glass Fiber Type & \multicolumn{2}{|c|}{ S-Glass } \\
\hline Fiber / Epoxy Ratio (wt ratio) & \multicolumn{2}{|c|}{$68 / 32$} \\
\hline Fiber Process & \multicolumn{2}{|c|}{ Filament Winding } \\
\hline Regulator Type & \multicolumn{2}{|c|}{ In Tank } \\
\hline Safety Factor & \multicolumn{2}{|c|}{2.25} \\
\hline
\end{tabular}

*@5,000 PSI tank, including $\mathrm{H}_{2}$ that can not pass through the regulator at $200 \mathrm{PSI}$. @10,000 PSI tank, including $\mathrm{H}_{2}$ that can not pass through the regulator at $400 \mathrm{PSI}$ 
We used netting analysis to calculate the carbon fiber requirements. The higher strength fiber (M30S) reduced weight by 8-9\%.

\begin{tabular}{|c|c|c|c|c|c|c|c|c|}
\hline \multirow{2}{*}{$\begin{array}{l}\text { Pres- } \\
\text { sure }\end{array}$} & \multirow[b]{2}{*}{ Vol. } & \multirow[b]{2}{*}{ Fiber } & \multirow[b]{2}{*}{$\begin{array}{l}\text { Liner } \\
\text { Type }\end{array}$} & \multicolumn{5}{|c|}{ Tank Component Weight (kg) } \\
\hline & & & & Liner & $\begin{array}{l}\text { Carbon Fiber } \\
\text { Composite }\end{array}$ & $\begin{array}{l}\text { Glass Fiber } \\
\text { Composite }\end{array}$ & Foam & $\begin{array}{l}\text { Tank } \\
\text { Total }\end{array}$ \\
\hline \multirow{4}{*}{$\begin{array}{c}5,000 \\
\mathrm{PSI}\end{array}$} & \multirow{4}{*}{$\begin{array}{l}255 \\
\text { Liter }\end{array}$} & \multirow{2}{*}{ M30S } & HDPE & 14.4 & \multirow{2}{*}{33.0} & \multirow{2}{*}{5.8} & \multirow{2}{*}{5.9} & \multirow{2}{*}{59} \\
\hline & & & $\mathrm{AL}$ & 14.8 & & & & \\
\hline & & \multirow{2}{*}{ T700S } & HDPE & 14.4 & \multirow{2}{*}{37.1} & \multirow{2}{*}{6.6} & \multirow{2}{*}{5.9} & \multirow{2}{*}{64} \\
\hline & & & $\mathrm{AL}$ & 14.8 & & & & \\
\hline \multirow{4}{*}{$\begin{array}{c}10,000 \\
\text { PSI }\end{array}$} & \multirow{4}{*}{$\begin{array}{l}155 \\
\text { Liter }\end{array}$} & \multirow{2}{*}{ M30S } & HDPE & 10.3 & \multirow{2}{*}{41.3} & \multirow{2}{*}{7.3} & \multirow{2}{*}{4.7} & \multirow{2}{*}{64} \\
\hline & & & $A L$ & 10.3 & & & & \\
\hline & & \multirow{2}{*}{ T700S } & HDPE & 10.3 & \multirow{2}{*}{46.6} & \multirow{2}{*}{8.2} & \multirow{2}{*}{4.7} & \multirow{2}{*}{70} \\
\hline & & & $\mathrm{AL}$ & 10.3 & & & & \\
\hline
\end{tabular}

Carbon Fiber/ Glass Factor= 0.85; Carbon Fiber Weight\% = 68; HDPE thickness= 0.25"; Al thickness $=0.09$ ", Tank weight without bosses and regulator

For the assumed liner thicknesses, the liner choice does not effect weight. 


\section{Appendix Carbon Fiber Options}

We believe aerospace grade properties and certifications will be required for composite compressed $\mathrm{H}_{2}\left(\mathrm{cH}_{2}\right)$ tank structures, consequently this sets the cost per pound in the $\$ 10-30$ per lb range.

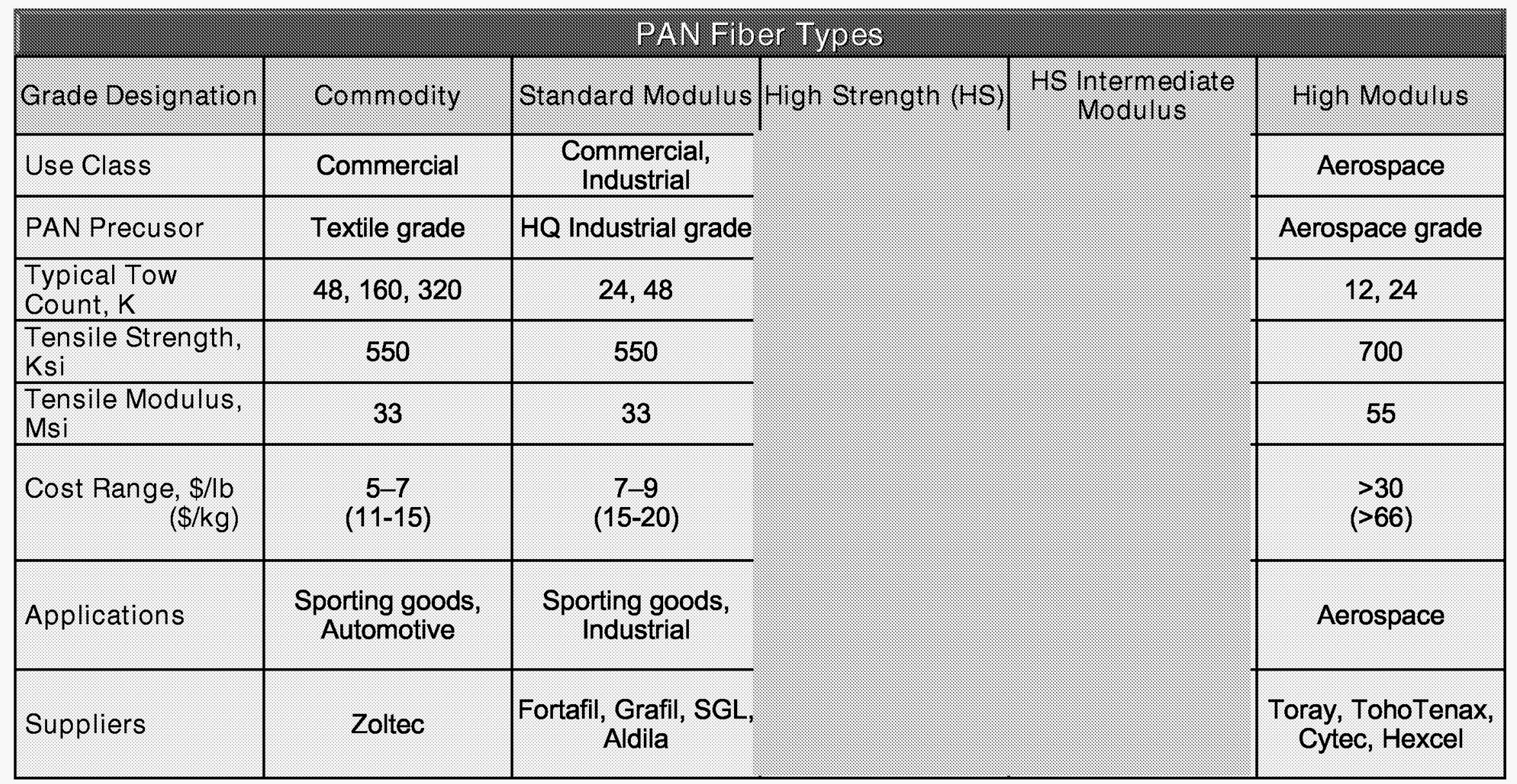




\section{Appendix Compressed Hydrogen Storage Cost Monte Carlo Simulation}

Monte Carlo simulation for the two pressures still leads to costs that are double the 2005 target for compressed hydrogen storage of $\$ 6 / \mathrm{kWh}$.

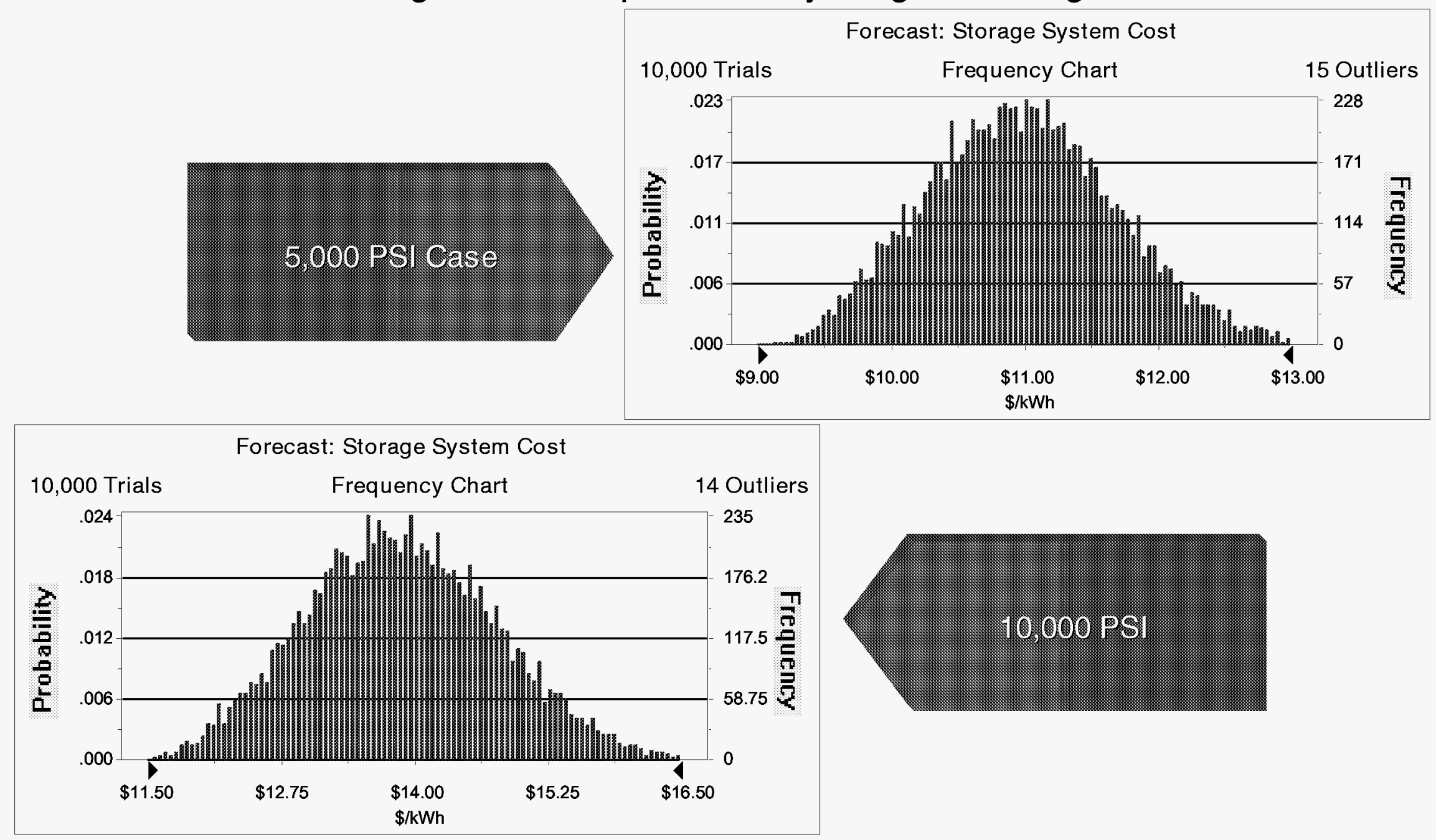


The direct hydrogen system cost estimate we shared with DOE in 2001 was based on developer's projections for the cost of $\mathrm{cH} 2$ storage.

\begin{tabular}{|c|c|}
\hline 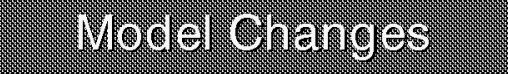 & cominemis: \\
\hline $\begin{array}{l}\text { Increased cost of } \\
\text { Hydrogen Storage System } \\
\text { from } \$ 12,00 \text { to } \$ 1,950 \\
\left(\$ 272 \text { to } \$ 348 / \mathrm{kg} \mathrm{H}_{2}\right)\end{array}$ & $\begin{array}{l}\text { Using activities-based cost analysis of the } \mathrm{cH}_{2} \text { storage system } \\
\text { Previous estimate was based on discussions with component developers - assuming high production } \\
\text { volumes, } 2010 \text { technology, including the whole storage system (a detailed analysis was not performed) } \\
\text { Amount of usable hydrogen stored changed from } 4.4 \mathrm{~kg} \text { to } 5.6 \mathrm{~kg}\end{array}$ \\
\hline $\begin{array}{l}\text { Eliminated Fuel Processor } \\
\text { Components }\end{array}$ & Reformate generator, reformate conditioner, fuel processor water supply \\
\hline $\begin{array}{l}\text { Eliminated Tailgas Burner } \\
\text { Components }\end{array}$ & Burner, fuel vaporizer, warm-up steam generator \\
\hline $\begin{array}{l}\text { Increased Net Parasitic } \\
\text { Power from } 6.1 \text { to } 8 \mathrm{~kW}\end{array}$ & $\begin{array}{l}\text { Consistent with ANL modeling of } 80 \mathrm{~kW} \mathrm{cH}_{2} \text { fuel cell system } \\
\text { Note that operating pressure was reduced from } 3 \text { to } 2.5 \mathrm{~atm}\end{array}$ \\
\hline $\begin{array}{l}\text { Increased CEM Cost from } \\
\$ 630 \text { to } \$ 900\end{array}$ & Based on recent discussions with CEM developers \\
\hline $\begin{array}{l}\text { Modified Heat Exchanger } \\
\text { Designs and Cost }\end{array}$ & $\begin{array}{l}\text { Based on new LMTD and heat loads from ANL modeling of } 80 \mathrm{~kW} \mathrm{cH} 2 \text { fuel cell system } \\
\text { Condenser increased in size significantly (minimal cost impact) }\end{array}$ \\
\hline $\begin{array}{l}\text { Eliminated Start-up } \\
\text { Batteries }\end{array}$ & $\begin{array}{l}\text { Assumes start-up time using stored hydrogen is nearly instantaneous } \\
\text { Equipment required for start-up under extreme conditions (e.g., sub-zero) were outside of this scope of } \\
\text { work }\end{array}$ \\
\hline
\end{tabular}

The cost of $\mathrm{cH}_{2}$ storage at 5,000 psi was found to be $\sim 30 \%$ higher on a per $\mathrm{kg}$ hydrogen basis using activities-based cost analysis. 


\section{The latest direct hydrogen fuel cell stack performance and cost parameters} also differ from the direct hydrogen estimate we prepared for DOE in 2001.

\begin{tabular}{|c|c|}
\hline Model Changes & Comments: \\
\hline $\begin{array}{l}\text { Increased Design Power } \\
\text { Rating from } 50 \text { to } 80 \mathrm{~kW}\end{array}$ & $\begin{array}{l}\text { - Consistent with } \mathrm{ANL} \text { drive-cycle modeling of } \mathrm{a} \mathrm{cH}_{2} \text { fuel cell vehicle with moderate } \\
\text { battery hybridization }\end{array}$ \\
\hline $\begin{array}{l}\text { Decreased Electrolyte } \\
\text { Cost from } 100 \text { to } 40 \$ / m^{2}\end{array}$ & Based on recent discussions with fuel cell and membrane developers \\
\hline $\begin{array}{l}\text { Increased Fuel Utilization } \\
\text { from } 95 \% \text { to } 100 \% \\
\text { (effective) }\end{array}$ & Consistent with current stack operation on pure hydrogen (i.e., no tailgas burner) \\
\hline $\begin{array}{l}\text { Decreased Pt loading } \\
\text { from } 0.4 / 0.4 \text { to } 0.2 / 0.1 \\
\mathrm{mg} / \mathrm{cm}^{2} \text { (Cathode/Anode } \\
\text { sides) }\end{array}$ & $\begin{array}{l}\text { Based on previous TIAX analysis that indicated a decrease in cathode catalyst loading } \\
\text { beyond } 0.2 \mathrm{mg} / \mathrm{cm}^{2} \text { does not reduce overall stack costs } \\
\text { Assume anode loading is half that of the cathode based on the observation that } \\
\text { hydrogen oxidation rate is higher than oxygen reduction rate }\end{array}$ \\
\hline $\begin{array}{l}\text { Decreased Design Cell } \\
\text { Voltage from } 0.8 \text { to } 0.69 \mathrm{~V}\end{array}$ & $\begin{array}{l}\text { Consistent with ANL modeling of } 50 \% \text { efficient } \mathrm{cH} 2 \text { fuel cell system at rated power - } \\
\text { resulting drive-cycle fuel economy is } 68 \mathrm{mpg}\end{array}$ \\
\hline $\begin{array}{l}\text { Increased Current } \\
\text { Density' from } 465 \text { to } 500 \\
\mathrm{~mA} / \mathrm{cm}^{2}\end{array}$ & $\begin{array}{l}\text { Assumption based on improvement in current density due to lower cell voltage ( } 0.69 \text { vs } \\
0.8) \text { that is somewhat offset by a reduction in Pt loading }\left(0.8 \mathrm{vs} 0.3 \mathrm{mg} / \mathrm{cm}^{2}\right) \text { - net result } \\
\text { is an increase in current density by }<10 \% \\
\text { Needs to be vetted by industry }\end{array}$ \\
\hline
\end{tabular}

\footnotetext{
${ }^{1}$ New current density at $100 \%$ excess air, 2.5 atm operating pressure ( $3 \mathrm{~atm}$ previously), and other conditions stated above.
} 
2004 System Cost Update 2001 - 2004 Direct H2 Fuel Cell Subsystem Changes

This table summarizes many of the performance and cost assumptions used in sizing and pricing the stack.

\begin{tabular}{|c|c|c|c|c|c|}
\hline Parameters & $\begin{array}{l}2000 \\
\text { Deformate }\end{array}$ & $\begin{array}{l}200 \text { t: } \\
\text { ieformate }\end{array}$ & $\begin{array}{l}2001 \\
\text { Dircot } t_{2}\end{array}$ & 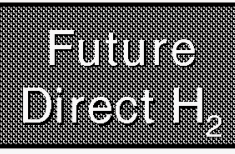 & $\begin{array}{l}2004 \\
\text { Direct } t_{2} \\
\end{array}$ \\
\hline Technology & 2000 & 2001 & 2001 & Future & 2004 \\
\hline Stack Gross Power (kW) & 56 & 56 & 56 & 56 & 88 \\
\hline Stack Power Density $\left(\mathrm{mW} / \mathrm{cm}^{2}\right)$ & 248 & 248 & 372 & 600 & $345^{*}$ \\
\hline Cell Current Density $\left(\mathrm{mA} / \mathrm{cm}^{2}\right)$ & 310 & 310 & 465 & 750 & 500 \\
\hline Membrane Cost $\left(\$ / \mathrm{m}^{2}\right)$ & 50 & 100 & 100 & 50 & 40 \\
\hline $\begin{array}{l}\text { Pt Loading (Cathode/Anode } \\
\left.\mathrm{mg} / \mathrm{cm}^{2}\right) \text { ) }\end{array}$ & $0.4 / 0.4$ & $0.4 / 0.4$ & $0.4 / 0.4$ & $0.2 / 0.1$ & $0.2 / 0.1$ \\
\hline Pt Cost $(\$ / k g)$ & 15,000 & 15,000 & 15,000 & 15,000 & 15,000 \\
\hline GDL Cost (\$/m²/Layer) & 9 & 14 & 16 & 16 & 16 \\
\hline Bipolar Plate Cost $\left(\$ / \mathrm{m}^{2}\right)$ & 23 & 24 & 24 & 24 & 28 \\
\hline CEM (\$/unit) & 630 & 630 & 630 & 500 & 900 \\
\hline
\end{tabular}

*@ $0.69 \mathrm{~V}$, all others at $0.8 \mathrm{~V}$ 
2004 System Cost Update 2001 - 2004 Direct H2 Fuel Cell Subsystem Cost Breakdown

The table below summarizes the component costs in the fuel cell subsystem.

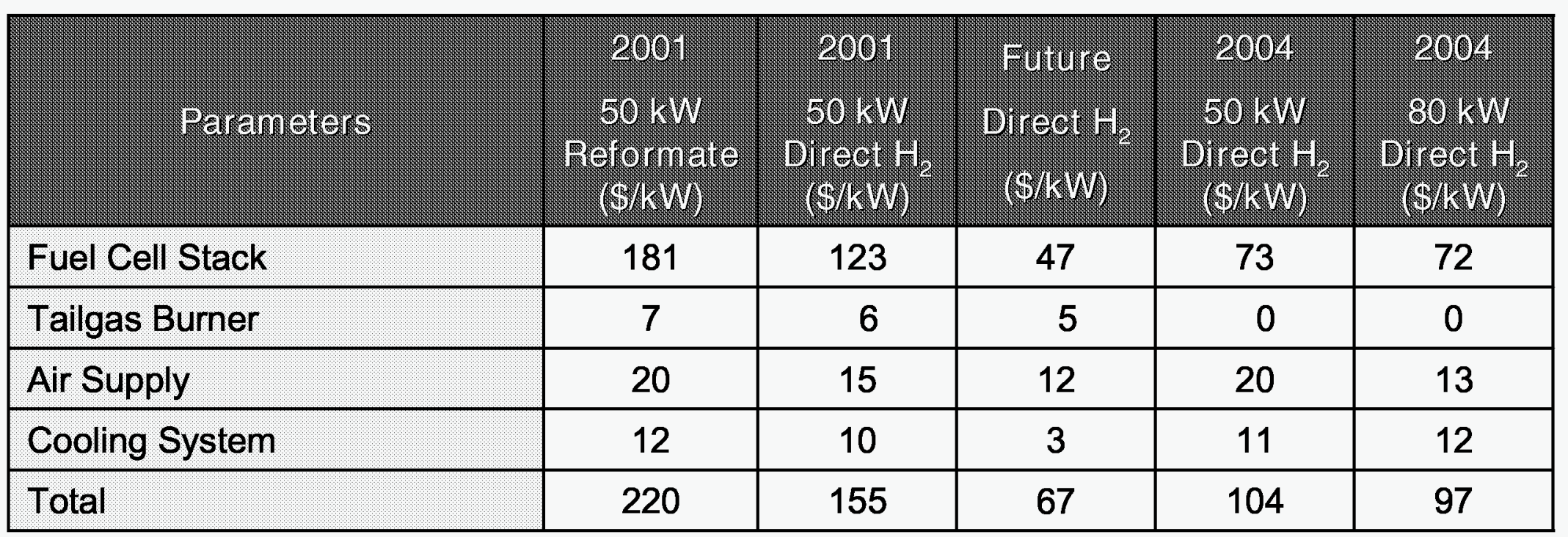

